Article

\title{
Optimal Channel Strategy for a Fresh Produce E-Commerce Supply Chain
}

\author{
Qian Zheng, Manman Wang * ${ }^{\mathbb{D}}$ and Feng Yang $\mathbb{B}$ \\ School of Management, University of Science and Technology of China, Hefei 230026, China; \\ zqustc96@mail.ustc.edu.cn (Q.Z.); fengyang@ustc.edu.cn (F.Y.) \\ * Correspondence: wmm2016@mail.ustc.edu.cn
}

Citation: Zheng, Q.; Wang, M.; Yang, F. Optimal Channel Strategy for a Fresh Produce E-Commerce Supply Chain. Sustainability 2021, 13, 6057. https://doi.org/10.3390/su13116057

Academic Editors: Per Engelseth, Richard Glavee-Geo,

Godfrey Mugurusi, Umar Burki, Robert Dahlstrom and Fahad Awaleh

Received: 23 April 2021

Accepted: 24 May 2021

Published: 27 May 2021

Publisher's Note: MDPI stays neutral with regard to jurisdictional claims in published maps and institutional affiliations.

Copyright: (c) 2021 by the authors. Licensee MDPI, Basel, Switzerland. This article is an open access article distributed under the terms and conditions of the Creative Commons Attribution (CC BY) license (https:/ / creativecommons.org/licenses/by/ $4.0 /)$.

\begin{abstract}
As an increasing number of firms move to omnichannel operation for business sustainability, it is also necessary for fresh produce firms to adopt an omnichannel model by integrating online and offline channels. We focus on a fresh produce supply chain consisting of a supplier who sells online directly and a physical store retailer. The purpose of this paper is to explore the optimal channel selection strategy considering the fresh-keeping efforts of supply chain members. Specifically, we examine the conditions under which the supply chain members should cooperate to adopt the deliver-from-store (DFS) model and further investigate the impact of consumers' freshness sensitivity and offline hassle cost on supply chain members' sales model options. Several important conclusions are shown as follows. First, the retailer's profit increases with the increasing freshness sensitivity in the dual-channel model, while it decreases if consumers are sufficiently sensitive to freshness in the DFS model. Second, if adopting the DFS model, online demand and total market demand expand, and the performance of the supplier and the retailer heavily depends on the size of the commission rate. Third, there always exists a win-win situation with an appropriate range of commission rate when the consumer's hassle cost is large. This paper contributes to the omnichannel strategy research of fresh produce supply chain management and the results provide management insights for the sustainable development of the fresh produce industry in the omnichannel retailing environment.
\end{abstract}

Keywords: omnichannel; fresh produce supply chain; freshness-keeping effort; channel strategy

\section{Introduction}

With the rapid development of information technology, online shopping has become a popular trend where consumers can purchase products at any time on websites or mobile applications. It has been reported that online sales have reached USD 1.82 trillion in China and the proportion of e-commerce in total sales accounted for nearly a quarter in 2020 [1]. In the fresh produce field, the market share of e-commerce reached USD 43.45 billion in 2019 and is expected to exceed USD 124 billion in 2023 [2]. An increasing number of traditional fresh produce enterprises such as Yiguo and Super Species are trying to involve e-commerce business to achieve long-term sustainable business development and pay more attention to multichannel management [3]. This indicates that there is a significant opportunity for fresh produce enterprises to improve their profitability by e-commerce in China.

The fast-growing e-commerce business expands organizations' market share and provides great convenience for consumers because people complete the purchase by clicking. Different from selling clothes, paper, and other necessities of life, freshness is a key factor that affects consumers making purchase decisions on fresh produce [4,5]. According to a survey in the United States, about 55\% of consumers refuse to buy online because of the uncertainty of produce freshness [6]. The e-commerce transactions make consumers unable to touch and inspect the product to ensure freshness before making a purchasing decision. Some freshness-conscious consumers may only buy from the offline channel 
because the quantity and quality of fresh produce are inevitably prone to loss in the process of transportation from the warehouse to the customer. Some research shows that the freshness of the produce determines the core competitiveness of the fresh produce company [7]. Freshness-keeping capability should be considered when measuring the operational efficiency of companies. Some scholars discussed the efforts made by companies to improve freshness. For example, Amazon invests in cold chain logistics to reduce product loss and improve product quality [8]. Super Species outsources its cold-chain service to an air transportation firm to transport cherries from overseas countries to China [9]. Besides, some suppliers, such as Zespri and Sysco, cooperate with downstream retailers who undertake the delivery and preservation of fresh produce.

In addition, supply chain management capability is a decisive factor restricting the successful development of fresh retailing [2]. With the complexity of the retail environment, Choudhary et al. [10] emphasized the increasing importance for companies to improve their supply chain sustainability performance. It is reported that $88 \%$ of fresh e-commerce firms post losses due to inefficient supply chain management capabilities [11]. The low degree of standardization of fresh produce, high freshness-keeping cost, and high transportation losses are huge challenges for enterprises [11,12]. For instance, the freshness-keeping cost of Yiguo accounts for $25-40 \%$ of sales and the average loss rate of fresh products is close to $20 \%$. Low standardization of production increases the retailer's cost of sales, and different product sizes also increase transportation costs. Therefore, unless companies cooperate deeply at each node of the supply chain, it is difficult for firms to address the above-mentioned issues and enhance supply chain sustainability.

Companies can improve consumers' shopping experience by deeply integrating online services, offline experience, and cold-chain logistics through channel innovation. Musso [13] emphasized that innovation in marketing channels requires collaboration and interactions across various entities within the supply chain network. How innovative channel management could be profitable is discussed by many studies, with examples from industry practices such as Walmart, Costco, TMALL, and Uniqlo [4,14,15]. According to a study by Melero et al. [16], $76 \%$ of managers put omnichannel operation as their top priority strategy. The traditional fresh produce supplier wholesales produce to retailers, and consumers buy through the offline channel. This loses part of the market demand because some consumers are far away from the store which is not convenient for offline shopping. With the development of online shopping, several organizations have realized the importance of channel integration in advancing profits. Many large-scale suppliers have opened up online channels by establishing self-operated websites or by operating online channels on third-party e-commerce platforms to cater to the online buying habits of consumers $[17,18]$. For example, the agricultural product supplier COFCO has established its website Womai.com and opened a self-run store on Taobao to enhance its market competitiveness. Meicai launched the mini-program "Meicai Mall" to establish a direct sales channel during the 2020 epidemic, leading to 800,000 users being added in a week. In addition, some fresh produce e-commerce firms also choose to cooperate with community retail stores or convenience stores to fulfill online orders, which is called the deliver from retailer's store (DFS) model. The fresh produce e-commerce firm is mainly responsible for the product sales and the retailer who operates the physical store provides a freshnesskeeping effort and delivery service to ensure product quality and distribution efficiency. For example, Meituan saves distribution costs and reduces fresh produce loss through implementing the DFS option. Dingdong reduces the freshness wastage rate to $3 \%$ by delivering from the nearest store. Consequently, to achieve freshness improvement and cost reduction, it is necessary for organizations to integrate online and offline channels by operating an omnichannel business model.

Although several omnichannel strategies have drawn considerable attention in the literature $[4,15,19]$, there is little research on the DFS option. In addition, Mishra et al. [20] presented that the success or failure of omnichannel strategies tends to be contingent upon consumers' perception of the delivered service. Some research has explored consumers' 
perception of channel transition fluency and channel uncertainty [21,22], but the perception of service efforts needs more attention. For the fresh produce supply chain management, some authors investigated how companies cooperate in freshness-keeping. However, the theoretical models usually describe the cooperation in a single channel [8,12]. The multi-channel supply chain shows that these models may be inadequate, and cross-channel cooperation between enterprises cannot be reflected. To fill these research gaps and explore the omnichannel strategy of fresh produce firms in practice, we consider a fresh produce supply chain in which a supplier independently operates the online channel and a retailer operates the offline channel. If consumers are sensitive to freshness, will the two firms have the opportunity to obtain more profit by integrating channels?

We put forward the following research questions:

1. What are the optimal decisions of the supplier and retailer when adopting the dualchannel model and DFS model? When can supply chain members benefit from these models?

2. How does consumer sensitivity to freshness and offline hassle cost affect the optimal performance of supply chain members?

3. Is the cooperative implementation of the DFS model beneficial to both parties, and under what situations can a win-win situation be achieved?

In order to solve the above problems, we consider a fresh produce supply chain composed of a supplier and a retailer, in which the supplier not only sells directly through the online channel but also wholesales fresh produce to the retailer, and the retailer sells produce through the offline channel. Based on the Stackelberg game, the supplier first decides the wholesale price and the online retail price, and then the retailer decides the offline retail price and freshness-keeping effort, both of which are based on the principle of maximizing profit. The optimal decisions of the two firms in the dual-channel model and cooperative omnichannel model are analyzed and compared. We find that the retailer's profit does not always increase with the increasing freshness sensitivity in the DFS model. After adopting the DFS model, the total market demand is expanded, and there is always a win-win situation when hassle cost is sufficiently large.

The remainder of this research is organized as follows. In the next section, we review the relevant literature. Section 3 describes the problem and assumptions. Section 4 develops two models to explore the optimal decisions of two firms in the centralized and decentralized structures. Section 5 compares the equilibrium results in two models and analyzes the optimal channel strategy for the supplier and the retailer. Numerical analysis is shown in Section 6. Finally, we put forward some managerial implications for operations managers and conclude the future research directions.

\section{Literature Review}

The literature related to our research mainly involves two literature streams: one is the stream of omnichannel retailing, and the other is studies on supply chain management of fresh produce.

\subsection{Omnichannel Retailing}

In recent years, research on omnichannel retail operations has become a hot issue, providing insights in terms of the conceptualization [19,23], strategic aspects $[4,15,18]$, and functional strategies to enhance organizations' channel marketing capabilities [24,25]. Regarding the definition of omnichannel, Verhoef et al. [26] explained omnichannel management as "optimizing the cross-channel customer experience and channel efficiency through collaborative management of numerous available channels and customer touchpoints". Omnichannel strategy is often viewed as an approach of innovation in marketing channels [25,27], referring to seamless integration between marketing channels [19]. Musso [28] presented that consumer switching across channels and devices is all part of the shoppers' omnichannel experience. Firms need to consider this to build a compelling retail proposition across all channels that delivers on experience, service, and logistics [29]. 
Many scholars have analytically explored retailers' omnichannel strategies. Some focused on the impact of the implementation of the buy-online-and-pick-up-in-store (BOPS) strategy on retailer's optimal decisions and profit [30-33]. The other investigated how the preorder-online-and-pickup-in-store (POPU) model affects the retailer's market share and profit under monopoly and competition situations $[34,35]$. There are also some studies on omnichannel returns. Zhang et al. [36] considered the situation where consumers can cancel orders offline and return products online. Nageswaran et al. combined the partial or full return policy [37] and Jin et al. investigated how the competitive environment affects retailer's cross-channel return strategy [38]. Omnichannel delivery is also attracting attention [14,39]. Yang and Zhang [40] found that the retailer will lose cross-selling revenue from an offline channel with ship-from-store (SFS). He et al. [41] put forward the online-first retailer adopts the ship-from-store option depending on the offline inventory cost. The above research focuses on the impact of retailers' online and offline channel integration on pricing and ordering decisions. Few studies consider the situation of supply chain firms cooperating to integrate channels. Besides, channel service plays an important role in the omnichannel strategy [42]; the research on the difference of service efforts between online and offline channels needs to be filled.

Moreover, studies are also related to consumer behavior and channel selection [21,22,43]. Rodriguez-Torrico et al. [23] confirmed that the inability to touch products online makes consumers hesitate to buy, and retailers should provide the same discounts and services between online and offline channels. Shen et al. [44] pointed out the impact of channel integration quality on consumer perception fluency. Kim et al. [45] empirically studied the drivers of the BOPS shopping behavior of consumers. However, they only focused on consumers' perception of channel uncertainty and channel transition fluency from an empirical perspective and ignored the impact of special product attributes on consumer behavior. In contrast to the extant research works, our study emphasizes that product freshness affects consumers' purchasing decisions and channel selection. We explore the impact of consumers' freshness sensitivity on the efficiency of channel integration.

\subsection{Fresh Produce Supply Chain Management}

In this subsection, we review the literature on supply chain management of fresh produce. In recent years, many studies have focused on pricing [46,47], cold chain distribution [9,48], and freshness-keeping effort decisions. Cai et al. [49] considered that the distributor is responsible for transportation and preservation in the two-level fresh supply chain and compared the equilibrium of the centralized and decentralized model. Wu et al. [8] combined logistics outsourcing services to explore retailer pricing and logistics provider fresh-keeping level decisions under different power structures. Liu et al. [50] emphasized the freshness-keeping effort and value-added service and explored the impact of retailers sharing demand information on the performance of supply chains. There are also many scholars concerned about cooperation in the fresh produce supply chain. Zheng et al. [51] studied the fresh-keeping effort decisions in a two-level supply chain and coordinated the supply chain through cost-sharing and revenue-sharing contracts to achieve a win-win situation. Chernonog [52] focused on advertising investment cooperation between the supply chain members who sell perishable produce and found that cooperation in a certain period of time is more beneficial to supply chain performance than non-cooperation. However, research on the interaction between fresh food supply chain companies was focused on a single channel and this limitation prompted the authors to explore cross-channel cooperation.

More attention has been paid to the channel strategies in the fresh produce industry. He et al. [3] first studied the impact of online fresh produce retailers using the pre-sales model in the market of offline grocery stores. Taking into account consumer preferences and freshness, Yang and Tang [53] further explored the optimal channel selection decision between the traditional retail model, the dual-channel model, and the $\mathrm{O} 2 \mathrm{O}$ model. $\mathrm{Hu}$ and $\mathrm{Xu}$ [54] investigated the BOPS strategy in an organic agricultural supply chain. Most 
relevant studies in fresh supply chain management consider multiple channels to operate independently. We tried to integrate marketing channels to make the scenario more realistic. Moreover, little effort has been made to study the delivery process. The difference in our research is that it focuses on a novel cooperation model for last-mile delivery, which realizes a buy online and deliver-from-store service.

The literature review highlights research gaps and the necessity of adopting omnichannel marketing for fresh produce supply chains. In summary, our research has the following differences from previous research. Firstly, most of the omnichannel strategies are implemented by the retailer alone in the previous studies. The research focuses on a single firm that decides whether to integrate its own online and offline channels to bring consumers a better purchase experience. In our study, we emphasize that the omnichannel strategy is implemented by the cooperation of the supplier and the retailer and explore the influence of commission rate on the willingness of both parties to implement an omnichannel strategy. Secondly, our work also explores how the freshness difference of different channels affects consumer purchasing decisions. When firms cooperate to adopt the omnichannel model, consumers can obtain the same level of freshness online and offline. Moreover, we consider the impact of offline hassle cost on the firms' choices. The result shows that when consumers' hassle cost is large, there always exists a win-win situation with an appropriate range of commission rate in the omnichannel model. Our research enriches the omnichannel strategy research of fresh produce supply chain management and proposes new management insights for the fresh produce firms implementing the omnichannel model.

\section{Model and Assumption}

In this section, we introduce a supply chain that contains a supplier and a traditional retailer who provide fresh produce, respectively. Considering a common competitive scenario where the supplier and the retailer run their own online and offline channels independently, consumers can buy fresh produce from the retailer's offline channel or supplier's online channel. There is a Stackelberg game between the two firms, in which the supplier is a leader, and the retailer is a follower. In the dual-channel model, the supplier sells the fresh produce to the retailer at the wholesale price $w$, and the retailer sells products to consumers in the physical store at the price $p_{r}$. The online channel is operated by the supplier directly, and the online price is represented by $p_{o}$. The supply chain structure is shown in Figure 1a. The retailer directly serves consumers offline and invests in cold chain preservation technology to provide freshness-keeping effort. The supplier focuses more on the sales process and lacks investment in preservation technology. Besides, long-distance transportation has a negative impact on the fresh produce quality, so the supplier is motivated to adopt the DFS model. Under the DFS model, the supplier cooperates with the brick-and-mortar retailer who is closer to consumers in the surrounding communities. Consumers' online orders are delivered from the retailer's nearest store, in order to minimize quality loss during transportation (such as JD Fresh and Meituan). The supplier will pay a percentage of online sales as the commission to the retailer, and the commission rate is represented by $r$. The wholesale price, online, and offline price are also noted by $w, p_{o}$ and $p_{r}$, which are consistent with dual channel mode. Figure $1 \mathrm{~b}$ shows the DFS model. For each model, we will discuss the optimal pricing, freshness-keeping effort, and the efficiency of the supply chain in the centralized and decentralized model. 


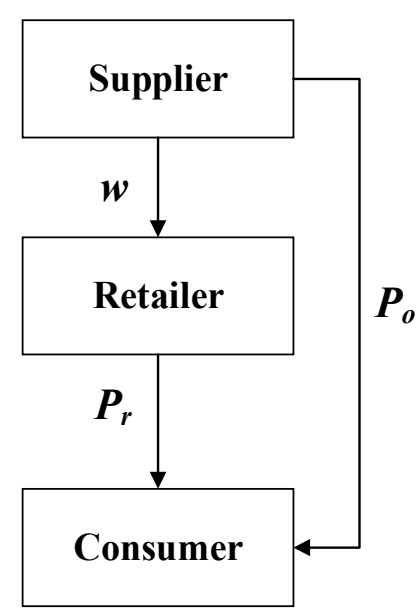

(a) Dual-channel model

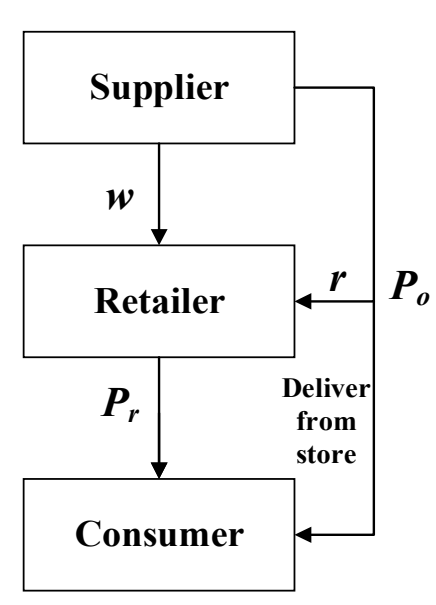

(b) DFS model

Figure 1. The difference of two sale models.

The purpose of this study is to explore whether the supplier and the retailer should cooperate to adopt the DFS sale model. The cooperation mechanism is the supplier directly selling products through an online channel and the retailer being responsible for delivering the products sold online. Due to the retailer making a freshness-keeping effort to the online sales, the supplier shares the online revenue with the retailer to stimulate the retailer. In order to distinguish different models, we use superscript 1 and 2 to represent the dualchannel model and the DFS model. The retailer and the supplier operate offline and online channels; the subscripts $r, s$ represent the retailer and the supplier. We use superscript $c$ to represent centralized decision-making. The major notation in our model is summarized in Table 1.

Table 1. Notation of the model.

\begin{tabular}{cl}
\hline Notation & Definition \\
\hline$v$ & Consumer's valuation of fresh produce \\
$u$ & Consumer's utility \\
$\mu$ & The matching degree of online produce, $\mu \in(0,1)$ \\
$\alpha$ & The freshness sensitivity of consumer, $\alpha \in(0,1)$ \\
$h$ & The hassle cost for consumer purchasing from an offline channel (e.g., search cost, \\
$c$ & travel cost, transaction cost) \\
$w$ & Delivery cost of the supplier \\
$p_{r}$ & Wholesale price of the supplier \\
$p_{o}$ & Retail price of the offline channel \\
$m$ & The increased freshness level due to the retailer's effort \\
$r$ & The commission rate of supplier sharing to the retailer, $r \in(0,1)$ \\
\hline
\end{tabular}

Similar to Chiang et al. [55] and Yang et al. [56], we assume that consumers are heterogeneous in their valuation of fresh produce. The valuation $v$ is uniformly distributed from 0 to 1 . Because consumers incur travel costs and search costs when purchasing offline, we denote all offline hassle costs as $h$ [30,57]. For consumers who buy online, they only need to click the mouse to place an order. The hassle cost of online is relatively small, so the online hassle cost is ignored in the following. The same assumption can be seen in the literature of Jin [38]. In addition, due to the low degree of standardization of agricultural products, the fresh produce purchased online may not match the requirements of consumers. For example, the taste, sweetness, and color of produce from different origins are different. We denote the matching degree of online produce as $\mu[53,58]$. Consumers obtaining the valuation from online channel purchasing is $\mu v$ for lack of physical inspection. 
Following the literature of Cai et al. [59] and Liu et al. [50], the quality of fresh produce can be represented by freshness. The freshness of produce affects the utility of consumers, which means the freshness level is higher and the products lose less which contributes to a higher market demand. We use a continuous variable $m$ to represent the freshness level increased by the retailer's effort to increase the freshness of produce. The sensitivity of consumers to freshness is $\alpha$. When consumers purchase products from an offline channel, they have an increased utility $\alpha m$ from the retailer's freshness-keeping effort. In line with the literature of Liu et al. [50] and Liu et al. [7], the freshness-keeping cost is $\frac{m^{2}}{2}$. In the DFS model, the supplier pays a percentage of online sales to the retailer as a commission, and the commission rate is represented by $r$.

We use the subscripts $r, o, b$ to describe offline channel (retail store), online channel, and DFS channel, respectively. In the dual-channel model, if consumers visit the store, the utility function is $u_{r}=v-p_{r}-h+\alpha m$. If consumers buy from an online channel, the utility function can be expressed as $u_{0}=\mu v-p_{0}$. When two firms cooperate to adopt the DFS model, consumer utility increases $\alpha m$ compared to a pure online channel, so consumer utility $u_{b}=\mu v-p_{o}+\alpha m$.

Moreover, we consider the retailer is close enough to consumers such as community retail stores, so the delivery cost of retailers can be negligible and assumed to be zero. Both the supplier and the retailer are risk-neutral and assume $\bar{\mu}-\alpha^{2}>0$, where $\bar{\mu}=\min [\mu,(1-\mu)]$.

\section{Model and Analysis}

In this section, we focus on the different operating models of fresh produce firms and explore the optimal decisions of the firms in the dual-channel model and DFS model. The supply chain structure affects the optimal decision-making of enterprises in the chain. We consider a centralized system in which stakeholders are viewed as a vertically integrated firm in Section 4.1. The firm controls all variables (online and offline price, the freshness-keeping effort) to maximize the profit of the whole supply chain system, which is meaningful for the development of the industry. In reality, companies always have a complicated competitive relationship, and they prefer to concentrate on optimizing their self-interest. Therefore, the decentralized supply chain in different channel structures needs to be explored. We analyze the decentralized supply chain in Section 4.2. The supplier leads the Stackelberg game. The sequence of the Stackelberg game is that the supplier sets the online price and wholesale price. Then the retailer determines the offline price and freshness-keeping effort based on the supplier's decisions.

\subsection{Centralized Model}

In the practice of the fresh produce industry, many large companies have the ability to simultaneously operate online and offline channels and deploy more cold chain facilities in the offline channel. For example, Hema and 7fresh adopt warehouse-store integration, using self-operated stores to provide fresh-keeping and delivery services for online orders. Consumers can purchase in-store, or place an online order and then wait for products to be delivered from the nearest store. Hence, we consider the situation of a centralized supply chain, where the supplier and retailer are regarded as a whole system. In order to ensure that the channel demand is positive, we assume that $\frac{2 c-c \alpha^{2}+\alpha^{2} \mu}{2 \mu}=h_{1}<h<h_{0}=$ $1-\mu, 0<c<c_{0}=\frac{\left(2-\alpha^{2}-2 \mu\right) \mu}{2-\alpha^{2}}$.

\subsubsection{Dual-Channel Model}

In the dual-channel model, the online channel and offline channel are operated respectively. Consumers can buy products through an online or offline channel. Firstly, we analyze consumers' channel choice. Consumers will purchase in-store if and only if $u_{r}>\max \left\{0, u_{0}\right\}$, while consumers will purchase online when $u_{0}>\max \left\{0, u_{r}\right\}$, otherwise, consumers will buy nothing. We solve the indifference points of consumers in the 
dual-channel model by $u_{r}=0, u_{o}=0, u_{r}=u_{0}$. Then we get $v_{r}=h+p_{r}-\alpha m, v_{0}=\frac{p_{0}}{\mu}$, $v_{r o}=\frac{h-p_{o}+p_{r}-m \alpha}{1-\mu}$. The consumer's purchase decision is shown in Figure 2.

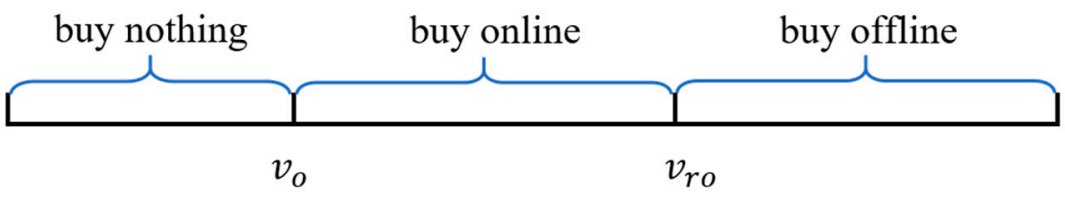

Figure 2. Consumer's purchasing decision in the dual-channel model.

The corresponding market division is determined by consumers' channel choice. Consumers who choose the online channel constitute online demand, and offline demand can be obtained in the same way. Thus, market demand is divided into three parts when $1>v_{r o}>v_{0}$, let $p_{1}=h-1+p_{r}-m \alpha+\mu, p_{2}=\left(h+p_{r}-m \alpha\right) \mu$, and we have:

$$
\begin{aligned}
& D_{r}^{1}=\left\{\begin{array}{c}
1-h-p_{r}+\alpha m \quad, p_{o}>p_{2} \\
1-\frac{h-p_{o}+p_{r}-m \alpha}{1-\mu}, p_{1}<p_{o}<p_{2} \\
0, p_{o}<p_{1}
\end{array}\right. \\
& D_{o}^{1}=\left\{\begin{array}{cc}
0 & , p_{o}>p_{2} \\
\frac{h-p_{o}+p_{r}-m \alpha}{1-\mu}-\frac{p_{o}}{\mu}, & p_{1}<p_{o}<p_{2} \\
1-\frac{p_{o}}{\mu} & , p_{o}<p_{1}
\end{array}\right.
\end{aligned}
$$

It can be seen from the demand function that when the online price is large enough, consumers will choose an offline channel, and online demand is 0 . When the online price is small enough, consumers are attracted by an online channel, and offline demand is 0 . Our research focuses on the simultaneous existence of two channels, so we only consider the situation when the online price is moderate, i.e., $p_{1}<p_{0}<p_{2}$, and then the demand function in the dual-channel model is obtained as follows:

$$
\begin{gathered}
D_{r}^{1}=1-\frac{h-p_{o}+p_{r}-m \alpha}{1-\mu} \\
D_{o}^{1}=\frac{h-p_{o}+p_{r}-m \alpha}{1-\mu}-\frac{p_{o}}{\mu}
\end{gathered}
$$

In a centralized model, the supplier and the retailer are viewed as vertically integrated firms who make decisions to maximize the benefit of the whole system. Therefore, the profit of the supply chain is composed of online channel profit and offline channel profit. The function of profit is as follows:

$$
\max \pi^{c 1}\left(p_{r}, p_{o}, m\right)=p_{r} D_{r}^{1}+\left(p_{o}-c\right) D_{o}^{1}-\frac{1}{2} m^{2}
$$

The central planner maximizes the profit by setting the optimal price and freshnesskeeping effort. The following proposition describes the optimal results.

Proposition 1. The equilibrium results with the Dual-channel model are:

$$
\begin{gathered}
\left\{\begin{array}{c}
p_{r}^{c 1 *}=\frac{(2-2 h)(1-\mu)+(c-\mu) \alpha^{2}}{2\left(2-\alpha^{2}-2 \mu\right)} \\
p_{o}^{c 1 *}=\frac{c+\mu}{2} \\
m^{c 1 *}=\frac{\alpha(1+c-h-\mu)}{2-\alpha^{2}-2 \mu}
\end{array}\right. \\
\left\{\begin{array}{c}
D_{r}^{c 1 *}=\frac{1+c-h-\mu}{2-\alpha^{2}-2 \mu} \\
D_{o}^{c 1 *}=\frac{\left(2 h-\alpha^{2}\right) \mu+\left(\alpha^{2}-2\right) c}{2 \mu\left(2-\alpha^{2}-2 \mu\right)}
\end{array}\right. \\
\pi^{c 1 *}=\frac{c^{2}\left(2-\alpha^{2}\right)+2\left(1-2(1+c) h+h^{2}+c \alpha^{2}\right) \mu-\left(2-4 h+\alpha^{2}\right) \mu^{2}}{4 \mu\left(2-\alpha^{2}-2 \mu\right)}
\end{gathered}
$$


Proposition 1 shows that optimal offline price and freshness-keeping efforts under the centralized model decrease with hassle cost, while the optimal online price is not affected. This is because consumers have low availability to visit stores with high hassle cost, and more people are willing to buy online, so the offline price will decrease in order to retain consumers. The growth of online profit cannot make up for the loss of offline, and will ultimately damage the profit of the supply chain. In addition, Proposition 1 indicates that the matching degree of online produce harms offline price and freshness-keeping effort but positively affects online price and supply chain profit. This reflects the fact that strengthening the standardization of fresh produce production is essential for supply chain sustainability.

Lemma 1. The impact of freshness sensitivity on the firm's equilibrium results under central dual-channel is as follows:

$$
\frac{\partial m^{c 1 *}}{\partial \alpha}>0, \frac{\partial \pi_{c}^{1 *}}{\partial \alpha}>0, \frac{\partial p_{r}^{c 1 *}}{\partial \alpha}>0, \frac{\partial p_{o}^{c 1 *}}{\partial \alpha}=0, \frac{\partial D_{r}^{c 1 *}}{\partial \alpha}>0, \frac{\partial D_{o}^{c 1 *}}{\partial \alpha}<0 .
$$

Lemma 1 shows that supply chain profit will increase with consumers' freshness sensitivity since the increased freshness effort raises the market demand. It is straightforward to find that higher freshness sensitivity leads to higher offline price and freshness-keeping effort. This is because consumers are more likely to buy offline when they pay attention to the quality of fresh produce. In this case, the supply chain performance is dominated by the offline channel. Furthermore, the online price is not affected by freshness sensitivity.

\subsubsection{Omnichannel Model}

Under the DFS model, the pure online channel moves to the DFS channel. Compared with the dual-channel model, a buy-online-and-deliver-from-store service is provided by the cooperation of the online channel and the offline channel, where consumers can choose to purchase directly in store, or after placing an order online, wait for delivery from the retailer's nearby store. Consumers will purchase from an offline channel if and only if $u_{r}>\max \left\{0, u_{b}\right\}$ or purchase from an online channel if and only if $u_{b}>\max \left\{0, u_{r}\right\}$, or otherwise, buy nothing. From $u_{r}=0, u_{b}=0$, and $u_{b}=u_{r}$, we obtain the indifference points $v_{r}=h+p_{r}-\alpha m, v_{b}=\frac{p_{0}-m \alpha}{\mu}, v_{r b}=\frac{h-p_{o}+p_{r}}{1-\mu}$. The consumer's purchasing decision is shown in Figure 3.

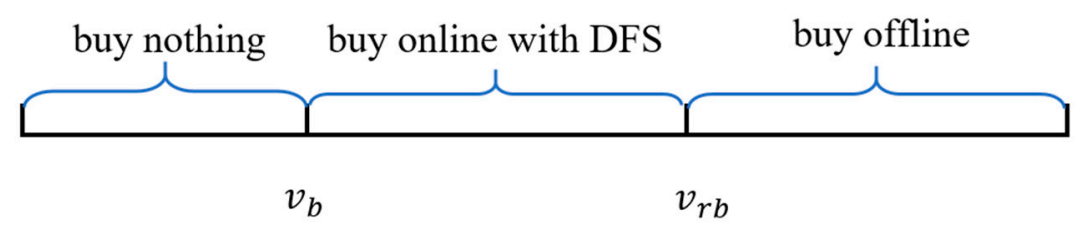

Figure 3. Consumer's purchasing decision in the DFS model.

When the online price is moderate $p_{r}+h+\mu-1<p_{o}<\mu\left(p_{r}+h-m \alpha\right)+m \alpha$, the demand for the offline channel and the DFS channel are both positive. We get the online and offline demand function after opening the DFS channel as follows:

$$
\begin{gathered}
D_{r}^{2}=1-\frac{h-p_{o}+p_{r}}{1-\mu} \\
D_{o}^{2}=\frac{h-p_{o}+p_{r}}{1-\mu}-\frac{p_{o}-m \alpha}{\mu}
\end{gathered}
$$


In the DFS model, the central planner's decision goal is:

$$
\max \pi_{c}^{2}\left(p_{r}, p_{o}, m\right)=p_{r} D_{r}^{2}+p_{o} D_{o}^{2}-\frac{1}{2} m^{2}
$$

The following proposition describes the equilibrium results.

Proposition 2. The equilibrium results with DFS model are:

$$
\begin{gathered}
\left\{\begin{array} { c } 
{ p _ { r } ^ { c 2 * } = \frac { 2 ( 1 - h ) \mu - \alpha ^ { 2 } ( 1 - h - \mu ) } { 2 ( 2 \mu - \alpha ^ { 2 } ) } } \\
{ p _ { o } ^ { c 2 * } = \frac { \mu ^ { 2 } } { 2 \mu - \alpha ^ { 2 } } } \\
{ m ^ { c 2 * } = \frac { \alpha \mu } { 2 \mu - \alpha ^ { 2 } } }
\end{array} \left\{\begin{array}{c}
D_{r}^{c 2 *}=\frac{1-h-\mu}{2(1-\mu)} \\
D_{o}^{c 2 *}=\frac{h}{2-2 \mu}-\frac{\alpha^{2}}{2\left(\alpha^{2}-2 \mu\right)}
\end{array}\right.\right. \\
\left\{\begin{array}{c}
\pi^{c 2 *}=\frac{1}{8}\left(2-4 h+\frac{2 h^{2}}{1-\mu}+\frac{2 \alpha^{2} \mu}{2 \mu-\alpha^{2}}\right)
\end{array}\right.
\end{gathered}
$$

When the DFS model is implemented, offline price and demand will still decrease with the hassle cost, and online demand is positively correlated with the hassle cost. After channel integration, online and offline channels have the same effort to preserve freshness. Thus, the level of freshness-keeping effort is independent of the hassle cost. The higher the matching degree of produce, the lower the uncertainty of consumers buying online, which hurts offline channel sales. Different from the dual-channel model, the impact of the matching degree of online products on the supply chain performance is more complicated. The reason is that the change of online demand with respect to the matching degree is dependent on hassle cost. When hassle cost is high, the supply chain performance increases with the matching degree.

Lemma 2. The impact of freshness sensitivity on the firm's equilibrium results under the DFS model is as follows:

$$
\frac{\partial \pi_{c}^{2 *}}{\partial \alpha}>0, \frac{\partial m^{c 2 *}}{\partial \alpha}>0, \frac{\partial p_{r}^{c 2 *}}{\partial \alpha}>0, \frac{\partial p_{o}^{c 2 *}}{\partial \alpha}>0, \frac{\partial D_{r}^{c 2 *}}{\partial \alpha}=0, \frac{\partial D_{o}^{c 2 *}}{\partial \alpha}>0 .
$$

Lemma 2 indicates that after implementing the DFS model, the profit of the supply chain, the optimal price, and the level of fresh-keeping effort will increase with the consumers' freshness sensitivity. Compared with the dual-channel model, online demand will increase with freshness sensitivity while offline demand is not affected. The results show that the advantage of an offline channel is weakened by adopting DFS.

\subsection{Decentralized Model}

In this subsection, we explore the optimal decision of the supplier and the retailer in the decentralized model. Considering that the supplier and the retailer separately operate the online channel and offline store, we first discuss the pricing of the two firms and the retailer's effort to maintain freshness and then explore the optimal decisions after the two firms cooperate to implement the DFS model. Market demand is divided by the utility of consumers in different channels. In the decentralized model, the retailer occupies the offline market, and the supplier owns the online market. The demand division is consistent with the centralized model. Based on the demand function given in Section 4.1, we obtain the profit function of both the dual-channel model and the DFS model. To ensure the channel demands are positive, $h<h_{0}$ and $c<c_{1}=\frac{\mu\left(1-\alpha^{2}-\mu\right)}{2-\alpha^{2}-\mu}$ is assumed in the following analysis. 


\subsubsection{Dual-Channel Model}

In the dual-channel model, the two firms separately decide the prices and the retailer decides freshness-keeping effort. The retailer's profit comes from offline channel revenue. The supplier's profit consists of two parts. Part of the revenue comes from the wholesale revenue and the other part comes from online sales. The profits are expressed as follows:

$$
\begin{aligned}
& \max \pi_{r}^{1}\left(p_{r}, m\right)=D_{r}^{1}\left(p_{r}-w\right)-\frac{1}{2} m^{2} \\
& \max _{s}^{1}\left(p_{o}, w\right)=w D_{r}^{1}+D_{o}^{1}\left(p_{o}-c\right)
\end{aligned}
$$

The decision sequence is that the supplier first decides the wholesale price and online sales price. The retailer determines the retail price and the level of freshness-keeping effort after obtaining the wholesale price information, and the consumer finally makes the purchase decision. The optimal decisions are as follows.

Proposition 3. The equilibrium results with dual-channel model are:

$$
\begin{gathered}
\left\{\begin{array}{c}
p_{r}^{1 *}=\frac{(1-h)\left(3-\alpha^{2}\right)+c(1-\mu)-4 \mu+\mu(3 h+\mu)}{2\left(2-\alpha^{2}-2 \mu\right)} \\
p_{o}^{1 *}=\frac{1}{2}(c+\mu)
\end{array}\right. \\
\left\{\begin{array}{c}
D_{r}^{1 *}=\frac{1+c-h-\mu}{2\left(2-\alpha^{2}-2 \mu\right)} \\
D_{o}^{1 *}=\frac{1}{4}\left(1-\frac{2 c}{\mu}+\frac{2 h-2 c-\alpha^{2}}{2-\alpha^{2}-2 \mu}\right) \\
\pi_{r}^{1 *}=\frac{(1+c-h-\mu)^{2}}{8\left(2-\alpha^{2}-2 \mu\right)}
\end{array}\right. \\
\left\{\begin{array}{c}
m^{1 *}=\frac{\alpha(1+c-h-\mu)}{2\left(2-\alpha^{2}-2 \mu\right)} \\
w^{1 *}=\frac{1-h}{2}
\end{array}\right. \\
\pi_{s}^{1 *}=\frac{c^{2}\left(2-\alpha^{2}-\mu\right)-2 c \mu\left(1+h-\alpha^{2}-\mu\right)+\mu\left(1+h^{2}-2 h(1-\mu)-\mu\left(\alpha^{2}+\mu\right)\right)}{4 \mu\left(2-\alpha^{2}-2 \mu\right)}
\end{gathered}
$$

Proposition 3 shows the retailer's price is higher than that of a centralized model, while the supplier's price is unchanged. The decentralized model makes the supplier more competitive, which means part of the offline demand moves online, and the total demand remains unchanged.

Moreover, as the offline channel demand decreases with the hassle cost, the retailer reduces the price to encourage consumers to buy in-store, which leads to lower offline profit. Intuitively, the freshness-keeping effort should increase as the hassle cost increases, but the result is the opposite due to the lower retail price. In addition, hassle cost also hurts the supplier's profit. The main reason is that the supplier reduces the wholesale price for an offline channel. Even if online demand increases, it is difficult to make up for the loss of offline wholesale profit. Therefore, when hassle cost is high, the supplier should strengthen product standardization and control online delivery costs to achieve more profit from online sales.

Lemma 3. The impact of freshness sensitivity on the firms' equilibrium results under the dualchannel model is as follows:

$$
\frac{\partial m^{1 *}}{\partial \alpha}>0, \frac{\partial \pi_{s}^{1 *}}{\partial \alpha}>0, \frac{\partial \pi_{r}^{1 *}}{\partial \alpha}>0, \frac{\partial p_{r}^{1 *}}{\partial \alpha}>0, \frac{\partial D_{r}^{1 *}}{\partial \alpha}>0, \frac{\partial D_{o}^{1 *}}{\partial \alpha}<0 .
$$

It is obvious that if consumers are more sensitive to freshness, they are more willing to buy in-store. Hence, offline demand increases with freshness sensitivity in Lemma 3. The increased demand motivates retailers to increase the fresh-keeping effort, and also contributes to higher profit. For the supplier, a simple intuition suggests that higher freshness sensitivity leads to lower online demand. The lower online demand hurts the supplier's profit. However, the profit of the supplier increases with freshness sensitivity, which indicates that the wholesale profit compensates for the online sales loss. 


\subsubsection{Omnichannel Model}

In the DFS model, the retailer delivers online orders for a supplier, which will incur the fresh-keeping cost. Suppliers pay $r$ proportion of online sales as a commission to encourage retailers to participate in cooperation. As is common in many studies [51,60,61], we assume that the commission rate is an exogenous variable. Therefore, the retailer's profit is composed of offline store sales and the commission paid by the supplier. Supplier's profit includes wholesale income and online direct sales. The profit functions for both parties are as follows.

$$
\begin{gathered}
\max _{r}^{2}\left(p_{r}, m\right)=D_{r}^{2}\left(p_{r}-w\right)+r p_{o} D_{o}^{2}-\frac{1}{2} m^{2} \\
\max _{s}^{2}\left(p_{o}, w\right)=w D_{r}^{2}+(1-r) p_{o} D_{o}^{2}
\end{gathered}
$$

Given the commission rate, the supplier first determines the wholesale price and online sales price, and the retailer determines the offline retail price and the effort after obtaining the wholesale price information. Finally, the consumer makes purchase decisions.

Proposition 4. The equilibrium results with the DFS model are:

$$
\begin{gathered}
\left\{\begin{array}{c}
p_{r}^{2 *}=\frac{3 r \alpha^{2}(-1+h+\mu)+\mu(3-3 h-\mu)}{4 \mu-4 r \alpha^{2}} \\
p_{o}^{2 *}=\frac{\mu^{2}}{2\left(-r \alpha^{2}+\mu\right)} \\
\left\{\begin{array}{l}
D_{r}^{2 *}=\frac{1-h-\mu}{4(1-\mu)} \\
D_{0}^{2 *}=\frac{1+h-\mu}{4-4 \mu}
\end{array}\right.
\end{array}\right\} \begin{array}{c}
m^{2 *}=\frac{r \alpha \mu}{2 \mu-2 r \alpha^{2}} \\
w^{2 *}=\frac{(1-h) \mu-r\left(\mu^{2}+\alpha^{2}(1-h-\mu)\right)}{2 \mu-2 r \alpha^{2}}
\end{array} \\
\left\{\begin{array}{c}
\pi_{r}^{2 *}=\frac{1}{16}\left(1+h\left(-2-\frac{h}{-1+\mu}\right)+\mu\left(-1+\frac{2 r \mu\left(-3 r \alpha^{2}+2 \mu\right)}{\left(-r \alpha^{2}+\mu\right)^{2}}\right.\right. \\
-2 *
\end{array}\right) \\
\pi_{s}^{2 *}=\frac{2 r(-1+\mu) \mu^{2}-r \alpha^{2}(-1+h+\mu)^{2}+\mu\left((-1+h)^{2}+2 h \mu-\mu^{2}\right)}{8\left(r \alpha^{2}-\mu\right)(-1+\mu)}
\end{gathered}
$$

From Proposition 4, we derive that the hassle cost has a negative impact on retailer's price in the DFS model, but the impact is weaker compared to the dual-channel mode. The retailer mitigates the impact of hassle cost by sharing cold chain capability. Thus, he becomes more competitive after cooperation. This result explains the phenomenon that most physical stores adopted the DFS option during the COVID-19 crisis when consumers worried about being infected at stores. Different from the results in the dual-channel, the retailer's freshness-keeping effort is not affected by hassle cost in this case. The reason is that the total market demand remains constant after adopting the DFS model and the retailer's freshness-keeping service covers all consumers. Furthermore, although online demand increases with hassle cost, online profit cannot offset the loss of wholesale profit.

Lemma 4. The impact of freshness sensitivity on the firms' equilibrium results under the DFS model is: $\frac{\partial \mathrm{p}_{\mathrm{r}}^{2 *}}{\partial \alpha}>0, \frac{\partial \mathrm{p}_{\mathrm{o}}^{2 *}}{\partial \alpha}>0, \frac{\partial \mathrm{m}^{2 *}}{\partial \alpha}>0, \frac{\partial \pi_{\mathrm{s}}^{2 *}}{\partial \alpha}>0$. For the retailer's profit, if $0<\alpha<\sqrt{\frac{\mu}{3 \mathrm{r}}}$, we have $\frac{\partial \pi_{r}^{2 *}}{\partial \alpha}>0$, if $\sqrt{\frac{\mu}{3 r}}<\alpha<\sqrt{\frac{1}{2}}$, we have $\frac{\partial \pi_{r}^{2 *}}{\partial \alpha}<0$.

Lemma 4 presents that after adopting the DFS model, consumers can enjoy the retailer's fresh-keeping service during online and offline purchases. The optimal prices of the supplier and retailer increase with consumer's freshness sensitivity. On the one hand, consumers have higher requirements for product quality and are willing to pay more for it. On the other hand, the retailer affords more fresh-keeping costs to meet consumers' demands. Therefore, the supplier and the retailer increase the price charged to consumers.

In addition, both the online price and wholesale price increase with freshness sensitivity, which increases supplier's profit. The impact of freshness sensitivity on retailer's profit is complicated. When consumers are less sensitive to freshness, the retailer's profit 
increases with the higher sensitivity. While the sensitivity is high, the retailer's profit will decrease. This is because when consumers' freshness sensitivity is within the specific limits, the retailer obtains more profit by raising prices. However, when the sensitivity is high enough, the retailer would make more effort to preserve freshness. The cost of freshness-keeping exceeds the benefits of price increases, which damages the interests of retailers.

\section{Equilibrium Analysis}

In this section, we first analyze the equilibrium results of the supply chain according to Propositions 1 and 2 and explore the performance of a supply chain under different channel strategies. Then we compare the optimal decisions of the supplier and the retailer in Propositions 3 and 4 and give the strategic selection conditions of both parties.

\subsection{Centralized Model}

According to Propositions 1 and 2, we compare the equilibrium price and freshnesskeeping effort in the dual-channel model and the DFS model. The impact of the DFS option on the performance of both channels and the supply chain is shown as follows.

Proposition 5. After the firm implements the DFS model, for the supply chain, $D^{c 2}>D^{c 1}$, $D_{r}^{c 2 *}<D_{r}^{c 1 *}, D_{o}^{c 2 *}>D_{o}^{c 1 *}, m^{c 2 *}>m^{c 1 *}, \pi^{c 2 *}>\pi^{c 1 *}$.

Proposition 5 shows that after two channels cooperate to adopt the DFS model, offline demand will decrease while online demand will increase. This can be explained by the fact that fresh-keeping effort is provided for the online channel, which may cause some consumers with high hassle cost to switch to online purchasing and attract more new consumers. Finally, the DFS model expands the total market demand. As the total market demand increases, the firm will make more efforts to meet the consumer demand.

Furthermore, the supply chain performance is better after adopting the DFS model. The online and offline prices increase with the increased freshness-keeping effort. The market demand under the DFS model is higher than that under the dual-channel model. As a result, the supply chain obtains more profit. This indicates that if the firm with online and offline channels implements the DFS option, he could be more confident in ensuring produce quality and expanding market share. The DFS strategy enhances the firm's sustainable profitability.

\subsection{Decentralized Model}

From Propositions 3 and 4, we investigate the differences in the equilibrium results of the supplier and the retailer in the dual-channel model and DFS model. The impact of the deliver-from-store option on the performance of both firms is shown as follows.

Proposition 6. The impact of the supplier and the retailer cooperating to implement the DFS model on the market demand is $D_{r}^{2 *}\left\langle D_{r}^{1 *}, D_{o}^{2 *}\right\rangle D_{o}^{1 *}, D_{t}^{2 *}>D_{t}^{1 *}$. For the freshness-keeping effort, if $r_{0}<r<1$, we have $m^{2 *}>m^{1 *}$, otherwise, $m^{2 *}<m^{1 *}$, where $r_{0}=\frac{(1+c-h-\mu) \mu}{\alpha^{2}(1+c-h-2 \mu)+2(1-\mu) \mu}$.

Proposition 6 indicates that the DFS model can obtain higher total market demand than the dual-channel model, which means the DFS model attracts new consumers into the market. Specifically, offline demand of the DFS model is less than that of the dual-channel model while online demand has the opposite result. The reason for this is that the offline channel loses the advantage of produce freshness, which leads to some offline consumers switching to the online channel. This result could suggest that the retailer and the supplier should cooperate to obtain more potential consumers.

The retailer's fresh-keeping effort depends on the commission rate paid by the supplier when they cooperate to adopt the DFS model. It is known that when the total market demand increases, the retailer needs to pay for more freshness-keeping efforts to meet the 
demand for the quality of fresh produce. It is suggested that the retailer trades off the commission and freshness-keeping effort cost when providing a cold chain package and delivery service.

Proposition 7. The impact of the supplier and the retailer cooperating to implement the DFS model on the two firms' profit is:

(1) for the retailer, if $r_{1}<r<\min \left[r_{2}, 1\right], \pi_{r}^{2 *}>\pi_{r}^{1 *}$; otherwise, $\pi_{r}^{2 *}<\pi_{r}^{1 *}$.

(2) for the supplier, if $0<r<r_{3}, \pi_{s}^{2 *}>\pi_{s}^{1 *}$; otherwise, $\pi_{s}^{2 *}<\pi_{s}^{1 *}$.

(3) if $r_{1}<r<r_{3}$, two firms can achieve a win-win situation.

The value of $r_{1}, r_{2}$, and $r_{3}$ can be seen in Appendix A for the derivation.

Proposition 7 illustrates that the choice of channel strategy for two firms heavily depends on the commission rate. The retailer is unwilling to implement the DFS model unless the commission rate is moderate. It is easy to understand that the retailer becomes better off with the DFS model when the commission rate is higher than a certain value. The retailer is worse off with a sufficiently high commission rate. The main reason for this is that a higher commission rate leads to a higher level of freshness-keeping effort, which increases the service effort cost and then brings little profit.

Furthermore, it is obvious that only when the commission rate is low can the supplier obtain a higher profit from cooperation. As the commission rate exceeds a certain threshold, the supplier has no incentive to implement the DFS model. There exists a Pareto improvement range, i.e., both the supplier and the retailer would achieve performance improvement when $r_{1}<r<r_{3}$. We confirm that the DFS strategy is not always better for both firms. The bargaining power of enterprises plays a critical role in the competitive situation. Both firms should carefully determine the commission contract to ensure that the cooperation is beneficial.

\section{Numerical Analysis}

\subsection{Sensitivity Analysis}

Considering the complexity of the commission rate threshold in Propositions 6 and 7, it is difficult to analyze whether the threshold is within the interval $[0,1]$, and determine whether there is a commission rate range that is beneficial to both firms after adopting the DFS model. In this section, we use numerical analysis to prove the existence conditions of Pareto improvement and obtain more management insights. Similar to the parameter settings in Yang and Tang [53], we have $c=0.05, \mu=0.5$. The value range of $h$ is [0, 0.5] and $\alpha$ is [0, 0.7] based on the assumption in Section 4.2.

Firstly, we explore the influence of the parameters on the threshold $r_{0}$ in Proposition 6 . In Figure 4, it can be seen that the commission rate threshold $\left(r_{0}\right)$ decreases with the hassle cost, which means that as the hassle cost increases, the retailer is more motivated to increase freshness-keeping effort. The reason is that hassle cost hurts the demand of the offline channel and the retailer will increase effort to attract consumers to purchase in-store, and thus a lower commission could motivate the retailer. On the contrary, the competitiveness of the online channel is weakened with lower hassle cost, so the supplier needs to pay a high commission to stimulate the retailer to improve fresh-keeping effort.

We take $\alpha$ as $0.2,0.4,0.6$ to explore the influence of freshness sensitivity on $r_{0}$. When the hassle cost is sufficiently small, the higher the consumer's requirements for the quality of fresh produce, the more the retailer is willing to improve freshness-keeping effort, leading to $r_{0}$ decreases. However, when the hassle cost is relatively high, even if consumers have high requirements for quality, the retailer lacks the motivation to improve freshness-keeping effort due to the low income from offline channel sales. Therefore, the supplier needs to pay more attention to the design of a commission contract to incentivize the retailer. 


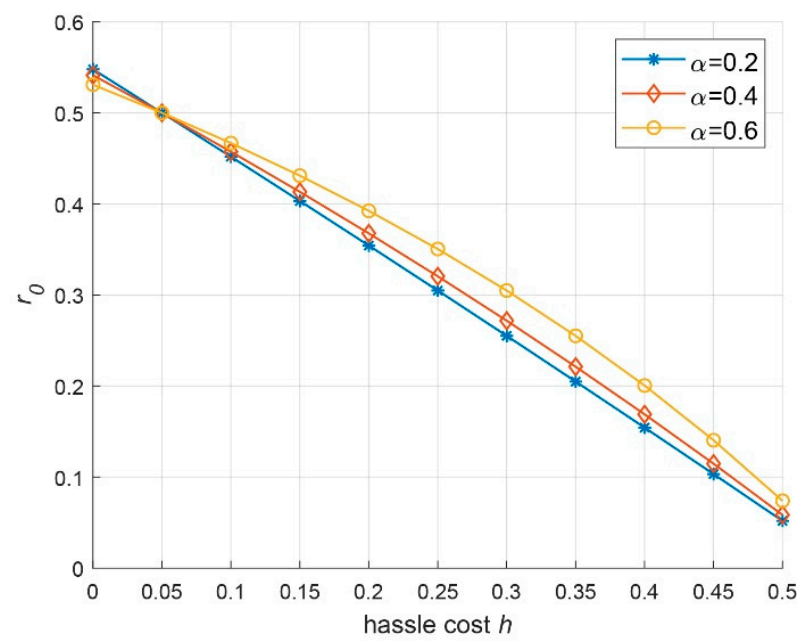

Figure 4. The impact of $\alpha, h$ on $r_{0}$.

Next, we discuss the impact of $\alpha, h$ on the thresholds $r_{1}, r_{2}, r_{3}$. From numerical analysis, we find that only when the freshness sensitivity of consumers is sufficiently high is $r_{2}$ in the interval $[0,1]$, otherwise, $r_{2}$ is always greater than 1 . Therefore, we mainly focus on the changes of threshold lines $r_{1}$ and $r_{3}$. Through Proposition 7, we know that the area above $r_{1}$ indicates that the retailer has an incentive to cooperate to adopt the DFS model, and the area below $r_{1}$ indicates that the retailer maintains the dual-channel model. For the supplier, the area below $r_{3}$ indicates that the supplier has an incentive to adopt the DFS model, and the area above $r_{3}$ indicates that the dual-channel model is better. It can be found from Figure 5 that with the increase in hassle cost, $r_{1}$ decreases while $r_{3}$ increases, which means the commission rate range of Pareto improvement gets larger, i.e., if the hassle cost is larger, there would be more chances for the two firms to benefit from the DFS model. This implies that higher hassle cost weakens the produce quality advantage of the retailer's offline channel, which gives the retailer more incentive to cooperate. Besides, the negative impact of hassle cost on an offline channel will reduce retailer's profit and affect supplier's wholesale profit, which encourages the supplier to cooperate to adopt DFS.

Let $\alpha$ be $0.1,0.2,0.4,0.6$ to observe the change of the lines of $r_{1}$ and $r_{3}$. As shown in Figure $5 \mathrm{a}$, d, we found that $r_{1}$ moves up with the increase of $\alpha$, indicating that the higher the consumers' freshness sensitivity, the lower the retailer's motivation to cooperate with the supplier. After cooperation, the retailer will lose the advantage of freshness. No matter how $\alpha$ changes, the retailer can always get more profit from the DFS model by setting a moderate commission rate. For the supplier, the threshold $r_{3}$ shifts to the right as $\alpha$ increases, which means adopting the DFS model may be detrimental to the supplier depending on hassle cost. The results indicate that the DFS model is more beneficial for the retailer than the supplier. There always exists a Pareto improvement area of commission rate if the hassle cost is high enough, which suggests that the two firms should cooperate to adopt the DFS model to achieve profit growth when it is inconvenient for consumers to visit the store.

Next, we let $\alpha=0.4$ to explore the impact of the matching degree of online fresh produce on the willingness to cooperate between two firms. The willingness of two firms to cooperate to implement DFS can be observed according to the changes of thresholds of $r_{1}$ and $r_{3}$. 


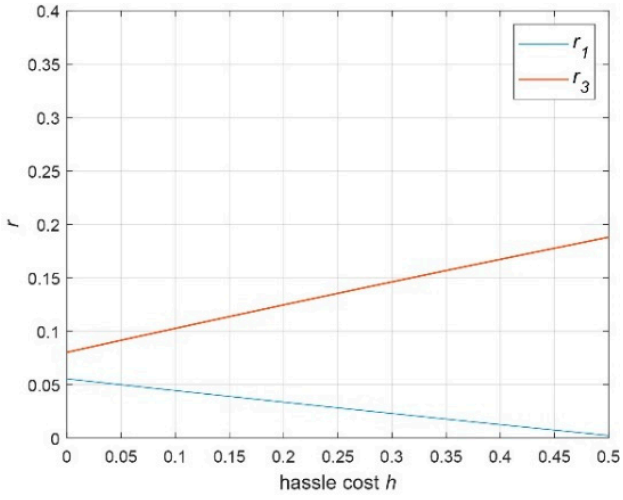

(a) $\alpha=0.1$

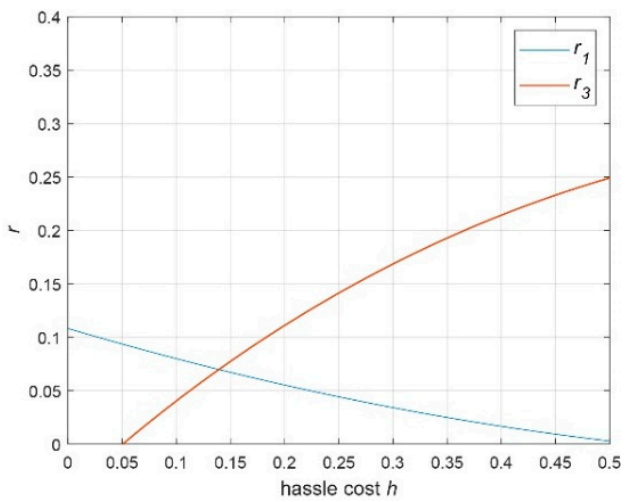

(c) $\alpha=0.4$

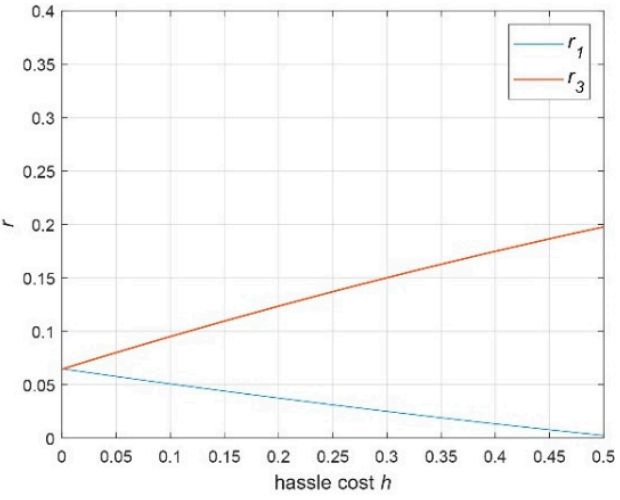

(b) $\alpha=0.2$

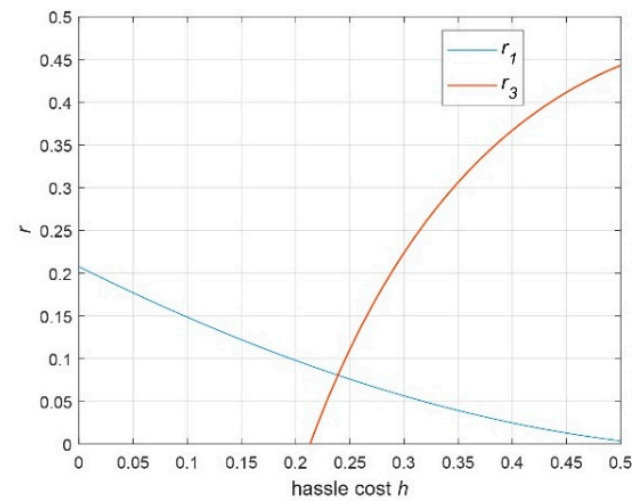

(d) $\alpha=0.6$

Figure 5. The impact of hassle cost on $r_{1}$ and $r_{3}$.

Figure 6 presents the impact of online fresh produce matching degree on firms' strategies. As the matching degree of fresh products increases, the threshold line $r_{1}$ moves down, indicating that the retailer is more willing to choose the DFS model. The rationale lies in the fact that the higher the standardization of fresh produce, the more consumers will switch to the online channel. There will be a more positive effect from the cooperation of adopting the DFS for the retailer. Therefore, the retailer is more willing to cooperate. For the supplier, the effect of $\mu$ on $r_{3}$ is more complicated, which is related to $h$. When hassle cost is sufficiently large, the supplier has less incentive to adopt DFS with the increasing matching degree of online produce.

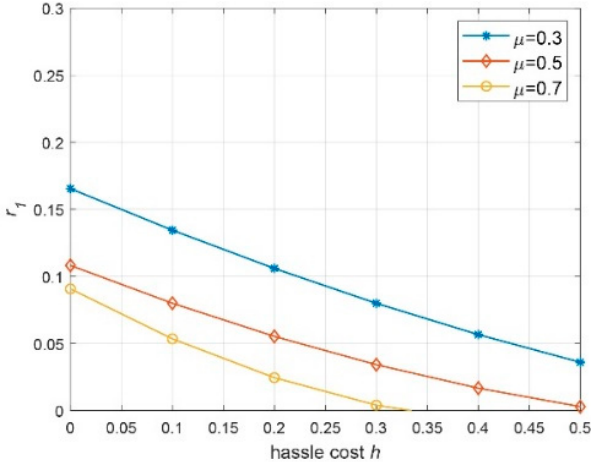

(a)

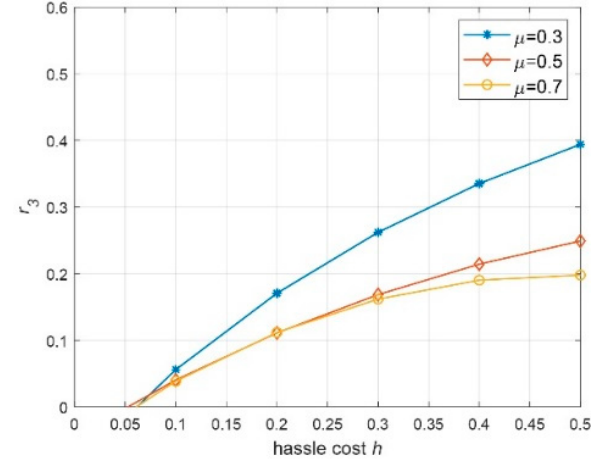

(b)

Figure 6. (a) The impact of $\mu$ on $r_{1}$. (b) The impact of $\mu$ on $r_{3}$. 


\subsection{Managerial Implications}

The research contributes to the growth of the omnichannel marketing strategy and provides insights into fresh produce supply chain management. Previous research on the omnichannel strategy neglects the fresh produce industry and the impact of consumer perception on purchasing decisions. Freshness plays a critical role in fresh produce management [42]. We put the consumers' freshness sensitivity into the theoretical model, which is more consistent with reality. The model helps firms to develop omnichannel marketing strategies by showing the impact of freshness sensitivity and hassle cost. Bayram, A., and Cesaret, B. [39] presented evidence that the retailer is always profitable in the DFS model, while we find that the DFS option is not always beneficial to the supply chain members. A proper cooperation contract could achieve a Pareto improvement. Additionally, in contrast to the extant research on integrating online and offline channels [40,41], we focus on adopting the omnichannel by cooperation between the supplier and the retailer, rather than the retailer integrating independently. Besides, rather than examining the inventory pooling strategy $[39,40]$ and the retailer's location advantage [41], we focus on the pricing decision and service effort. This study demonstrates that the retailer may reduce the freshness-keeping effort with sufficiently high freshness sensitivity after implementing DFS mode. This is different from the previous research [53] presented, which states that the effort always increases by integrating channels.

Our study provides insights into the channel cooperation of fresh produce enterprises by combining the hassle cost and consumer freshness sensitivity. Increasing freshness sensitivity does not always incentivize the supplier to adopt the DFS option. When the hassle cost is low, cooperation harms the supplier. Firms should identify the hassle cost of consumers visiting the store in terms of transaction costs, travel distance, congestion, and out-of-stock risk. When consumers have difficulties visiting the store, the supplier cooperating with the retailer to adopt the omnichannel strategy is more profitable. Furthermore, firms need to improve bargaining power to obtain more profit from cooperation. From the perspective of the development of the fresh produce e-commerce industry, the supply chain members centralizing making decisions to implement omnichannel strategy creates more value.

\section{Conclusions}

\subsection{Findings and Insights}

The rapid development of online shopping has prompted fresh produce firms to integrate online and offline channels. To make full use of the advantages of different channels and improve operational efficiency, many companies cooperate with others. A two-level supply chain including a supplier and a retailer has been established. The retailer operates an offline channel, and the supplier sells directly through an online channel. Considering consumer concern about the freshness of produce, we explore the performance of a novel retail channel called the DFS model where the supplier's online order is delivered to and freshness-keeping effort is provided by the retailer's store so that online consumers can be provided with the same level of quality fresh produce as offline consumers by channel integration. The supplier pays commission to the retailer for cooperation. We investigate the optimal decisions of both parties in the dual-channel model and the DFS model and identify the situations under which two firms can benefit from adopting an omnichannel option. Our main results are as follows.

In fresh produce retailing, produce quality (freshness) is an important feature. Firstly, we find that in the dual-channel model, the profit of two firms will increase as consumers' freshness sensitivity increases. However, after implementing the DFS model, if consumers are sufficiently sensitive to freshness, the retailer's profit decreases with consumers' freshness sensitivity because of the increased freshness-keeping cost. Secondly, the adoption of the DFS model will expand online demand and total market demand. The freshnesskeeping effort is always increased in a centralized model while the relationship depends on the commission rate in a decentralized model. The retailer will increase fresh-keeping 
efforts only when the commission rate is relatively high. In addition, the supply chain always benefits from the DFS model in a centralized model. For the decentralized model, the performance of two firms after adopting the DSF model heavily depends on the commission rate. When the commission rate is sufficiently low, the supplier can benefit from DFS, while the retailer performs better when the commission rate is moderate. Numerical analysis results show that there is always a win-win situation when the hassle cost is large enough. Finally, we also analyze the impact of online produce matching degree on the firms' willingness to cooperate to adopt DFS. The retailer's motivation increases with the higher matching degree while the supplier's motivation is related to hassle cost.

Our study provides some new management insights for supply chain management of fresh produce. First, as consumers have higher requirements for the quality of fresh produce, firms should integrate the channels to provide the same service effort to attract more potential consumers. The omnichannel strategy could improve the retailer's freshness-keeping effort, which contributes to ensuring fresh food safety and human health. Second, when both parties choose to carry out the omnichannel strategy, they need to investigate the business conditions, such as the convenience for consumers visiting physical stores and consumers' requirements for freshness. For the consumers with low hassle cost, they should take measures (e.g., compensation for freshness loss, return policy) to relieve the freshness sensitivity of consumers. For consumers with high hassle cost, firms should advertise the freshness preservation technology to enhance consumers' emphasis on the freshness sensitivity. Then, a moderate commission contract would be profitable for both parties. The bargaining power determines who obtains more profit from the omnichannel strategy. Finally, in the omnichannel environment, the interaction between channels is a beneficial action rather than a complete competition. Suppliers and retailers operating in different channels should take a long-term perspective on channel integration and strengthen cooperation to make full use of online and offline advantages, which is conducive to the sustainable development of the fresh produce e-commerce industry.

\subsection{Limitations and Future Directions}

Although our study captures consumer freshness requirements and provides some new insights for supply chain management of fresh produce, there are several limitations and possible extensions worth pursuing that can further deepen our understanding of retail channel management. First of all, we assume the supply chain is stable, and related risks of the fresh produce supply chain are left out. However, the risks (such as demand uncertainty, supply price volatility, and uncertainty of preservation technology) may cause companies to bear dramatic losses. Controlling the supply chain risk has been studied more recently $[62,63]$ and the impact of the supply chain risk could be explored for an extension. Besides, to make our research more realistic, we could use practical data to test our results in the future. Second, this study assumes that the supplier improves the freshness level of online produce by cooperating with the retailer and neglects the waiting cost for purchasing online. The possibility of the supplier self-investing in cold chain technology could be investigated, the waiting cost could be included in the model in the future. Thirdly, considering consumer segmentation is more realistic. For example, highly freshness-sensitive consumers never purchase online and lowly freshness-sensitive consumers choose the channel based on utility. Finally, we only pay attention to the omnichannel model of deliver-from-store. More omnichannel models are worthy of studies, such as pickup in-store or self-lifting cabinets [20,45].

Author Contributions: Conceptualization, F.Y.; formal analysis, M.W.; funding acquisition, F.Y.; investigation, Q.Z.; methodology, Q.Z. and M.W.; supervision, F.Y.; writing—original draft preparation, Q.Z.; writing-review and editing, M.W. All authors have read and agreed to the published version of the manuscript.

Funding: This research was funded by the National Natural Science Foundation of China, grant number $71991464 / 71991460,71921001$ and 71631006. 
Institutional Review Board Statement: Not applicable.

Informed Consent Statement: Not applicable.

Data Availability Statement: Not applicable.

Conflicts of Interest: The authors declare no conflict of interest.

\section{Appendix A}

Proof of Proposition 1. Under the centralized model, the vertically integrated firm takes decisions to maximize the whole supply chain system. Therefore, the single firm simultaneously decides price and freshness-keeping effort. From the assumption, we know $\bar{\mu}-\alpha^{2}>0, \bar{\mu}=\min [\mu,(1-\mu)]$. First, we prove the supply chain profit function is concave. According to Equation (3), the decision variables are $p_{r}, p_{0}, m$; it is easy to express the first and second derivatives of $\pi^{c 1}$ with respect to these decision variables: $\frac{\partial \pi^{c 1}}{\partial p_{r}}=$ $1+\frac{c+h-2 p_{o}+2 p_{r}-m \alpha}{-1+\mu} \frac{\partial^{2} \pi^{c 1}}{\partial p_{r}{ }^{2}}=\frac{2}{-1+\mu}<0, \frac{\partial \pi^{c 1}}{\partial p_{o}}=\frac{c-2 p_{o}+h \mu+2 p_{r} \mu-m \alpha \mu}{\mu-\mu^{2}}, \frac{\partial^{2} \pi^{c 1}}{\partial p_{o}{ }^{2}}=-\frac{2}{\mu-\mu^{2}}<0$, $\frac{\partial \pi^{c 1}}{\partial m}=\frac{m-\left(c-p_{o}+p_{r}\right) \alpha-m \mu}{-1+\mu}, \frac{\partial^{2} \pi^{c 1}}{\partial m^{2}}=\frac{1-\mu}{-1+\mu}<0$. We define the hessian matrix of $\pi^{c 1}$ as $H$, $H\left(\pi^{c 1}\right)=\left[\begin{array}{ccc}\frac{2}{-1+\mu} & \frac{\alpha}{1-\mu} & \frac{2}{1-\mu} \\ \frac{\alpha}{1-\mu} & \frac{1-\mu}{-1+\mu} & \frac{\alpha}{-1+\mu} \\ \frac{2 \mu}{\mu-\mu^{2}} & \frac{-\alpha \mu}{\mu-\mu^{2}} & \frac{-2}{\mu-\mu^{2}}\end{array}\right]$. Since $(1-\mu)-\alpha^{2}>0$ with the assumption, we have the second-order principal minor determinant $\left|\begin{array}{cc}\frac{2}{-1+\mu} & \frac{\alpha}{1-\mu} \\ \frac{\alpha}{1-\mu} & \frac{1-\mu}{-1+\mu}\end{array}\right|=\frac{2-\alpha^{2}-2 \mu}{(1-\mu)^{2}}>0$. The thirdorder principal minor determinant is negative: $\left|\begin{array}{ccc}\frac{2}{-1+\mu} & \frac{\alpha}{1-\mu} & \frac{2}{1-\mu} \\ \frac{\alpha}{1-\mu} & \frac{1-\mu}{-1+\mu} & \frac{\alpha}{-1+\mu} \\ \frac{2 \mu}{\mu-\mu^{2}} & \frac{-\alpha \mu}{\mu-\mu^{2}} & \frac{-2}{\mu-\mu^{2}}\end{array}\right|=\frac{2\left(-2+\alpha^{2}+2 \mu\right)}{(1-\mu)^{2} \mu}<0$ It is straightforward that the hessian matrix is negative definite. Therefore, the profit $\pi^{c 1}$ is joint concave in $\left(p_{r}, m, p_{o}\right)$. There exits the optimal solution of Equation (3). Then, we calculate the solutions by solving the first-order conditions. Let $\frac{\partial \pi^{c 1}}{\partial p_{r}}=0, \frac{\partial \pi^{c 1}}{\partial p_{o}}=0, \frac{\partial \pi^{c 1}}{\partial m}=0$. We obtain the optimal offline price $p_{r}^{c 1 *}=\frac{-2+2 h-c \alpha^{2}+\left(2-2 h+\alpha^{2}\right) \mu}{2\left(-2+\alpha^{2}+2 \mu\right)}$, the optimal online price $p_{o}^{c 1 *}=\frac{c+\mu}{2}$ and optimal freshness-keeping effort $m^{c 1 *}=\frac{\alpha(-1-c+h+\mu)}{-2+\alpha^{2}+2 \mu}$. Substituting $p_{r}^{c 1 *}$, $p_{o}^{c 1 *}, m^{c 1 *}$ into Equations (1)-(3), we derive the demand of online and offline channels and the optimal profit in the dual-channel model.

Proof of Proposition 2. Similar to the dual-channel model, the vertically integrated firm determines the optimal price and freshness effort simultaneously. From Equation (6), we solve the first and second derivatives of $\pi^{c 2}$ with respect to $p_{r}, p_{0}, m$. It is easy to find that $\frac{\partial \pi^{c 2}}{\partial p_{r}}=1+\frac{h-2 p_{o}+2 p_{r}}{-1+\mu}, \frac{\partial^{2} \pi^{c 2}}{\partial p_{r}^{2}}=\frac{2}{-1+\mu}<0, \frac{\partial \pi^{c 2}}{\partial p_{o}}=\frac{2 p_{o}+m \alpha(-1+\mu)-\left(h+2 p_{r}\right) \mu}{(-1+\mu) \mu}, \frac{\partial^{2} \pi^{c 2}}{\partial p_{o}{ }^{2}}=$ $\frac{2}{(-1+\mu) \mu}<0, \frac{\partial \pi^{c 2}}{\partial m}=-m+\frac{p_{o} \alpha}{\mu}, \frac{\partial^{2} \pi^{c 2}}{\partial m^{2}}=-1<0$. Let $H$ be the hessian matrix of $\pi^{c 2}$. $H\left(\pi^{c 2}\right)=\left[\begin{array}{ccc}\frac{2}{-1+\mu} & \frac{2}{1-\mu} & 0 \\ \frac{2}{1-\mu} & \frac{2}{(-1+\mu) \mu} & \frac{\alpha}{\mu} \\ 0 & \frac{\alpha}{\mu} & -1\end{array}\right]$. The second-order principal minor determinant of $H:\left|\begin{array}{cc}\frac{2}{-1+\mu} & \frac{2}{1-\mu} \\ \frac{2}{1-\mu} & \frac{2}{(-1+\mu) \mu}\end{array}\right|=\frac{4}{\mu-\mu^{2}}>0$; Since $\mu-\alpha^{2}>0$, we have the third-order principal minor determinant of $H\left|\begin{array}{ccc}\frac{2}{-1+\mu} & \frac{2}{1-\mu} & 0 \\ \frac{2}{1-\mu} & \frac{2}{(-1+\mu) \mu} & \frac{\alpha}{\mu} \\ 0 & \frac{\alpha}{\mu} & -1\end{array}\right|=\frac{-2 \alpha^{2}+4 \mu}{(-1+\mu) \mu^{2}}<0$. The hessian matrix of $\pi^{c 2}$ is negative definite. Therefore, the profit $\pi^{c 2}$ is joint concave in $\left(p_{r}, m, p_{o}\right)$. Let $\frac{\partial \pi^{c 2}}{\partial p_{r}}=0$, 
$\frac{\partial \pi^{c 2}}{\partial p_{0}}=0, \frac{\partial \pi^{c 2}}{\partial m}=0$. By solving the first-order conditions simultaneously, we get the optimal decisions of $p_{r}^{c 2 *}=\frac{2(1-h) \mu-\alpha^{2}(1-h-\mu)}{2\left(2 \mu-\alpha^{2}\right)}, p_{o}^{c 2 *}=\frac{\mu^{2}}{2 \mu-\alpha^{2}}, m^{c 2 *}=\frac{\alpha \mu}{2 \mu-\alpha^{2}}$. Substituting $p_{r}^{c 1 *}, p_{o}^{c 1 *}$, $m^{c 1 *}$ into Equations (1), (2) and (4), we derive the demand of online and offline channels and the optimal supply chain profit in the DFS model.

Proof of Proposition 3. From Equation (7) there are two decision variables $p_{r}$ and $m$ in the profit function of retailer, and we can find that $\frac{\partial \pi_{r}^{1}}{\partial p_{r}}=1-\frac{-h+p_{0}-2 p_{r}+w+m \alpha}{-1+\mu}, \frac{\partial^{2} \pi_{r}^{1}}{\partial p_{r}{ }^{2}}=$ $\frac{2}{-1+\mu}<0, \frac{\partial \pi_{r}^{1}}{\partial m}=-m+\frac{\left(-p_{r}+w\right) \alpha}{-1+\mu}, \frac{\partial^{2} \pi_{r}^{1}}{\partial m^{2}}=-1<0$, then the Hessian matrix of the retailer is $H\left(p_{r}, m\right)=\left|\begin{array}{cc}\frac{2}{-1+\mu} & -\frac{\alpha}{-1+\mu} \\ -\frac{\alpha}{-1+\mu} & -1\end{array}\right|=\frac{2-\alpha^{2}-2 \mu}{(-1+\mu)^{2}}$. With the assumption $\bar{\mu}-\alpha^{2}>0$, obviously, the Hessian matrix is negative definite. Let $\frac{\partial \pi_{r}^{1}}{\partial p_{r}}=0, \frac{\partial \pi_{r}^{1}}{\partial m}=0$, we have the reaction function of the retailer $p_{r}=\frac{-1+h-p_{0}+w\left(-1+\alpha^{2}\right)+2 \mu-h \mu+\left(p_{o}+w-\mu\right) \mu}{-2+\alpha^{2}+2 \mu}, m=\frac{\alpha\left(-1+h-p_{o}+w+\mu\right)}{-2+\alpha^{2}+2 \mu}$. By substituting these reaction functions into Equation (8), we obtain the profit function of the supplier. Then we have $\frac{\partial \pi_{s}^{1}}{\partial w}=\frac{-1+c+h-2 p_{o}+2 w+\mu}{-2+\alpha^{2}+2 \mu}, \frac{\partial^{2} \pi_{s}^{1}}{\partial w^{2}}=\frac{2}{-2+\alpha^{2}+2 \mu}<0$, $\frac{\partial \pi_{s}^{1}}{\partial p_{o}}=\frac{1}{2}+\frac{c-2 p_{0}}{\mu}+\frac{-2\left(c+h-2 p_{o}+2 w\right)+\alpha^{2}}{2\left(-2+\alpha^{2}+2 \mu\right)}, \frac{\partial^{2} \pi_{s}^{1}}{\partial p_{0}^{2}}=\frac{2\left(2-\alpha^{2}-\mu\right)}{\mu\left(-2+\alpha^{2}+2 \mu\right)}<0$, the Hessian matrix of the supplier is $H\left(p_{0}, w\right)=\left|\begin{array}{cc}\frac{2}{-2+\alpha^{2}+2 \mu} & \frac{2}{2-\alpha^{2}-2 \mu} \\ \frac{2}{2-\alpha^{2}-2 \mu} & \frac{2\left(2-\alpha^{2}-\mu\right)}{\mu\left(-2+\alpha^{2}+2 \mu\right)}\end{array}\right|=\frac{4}{\mu\left(2-\alpha^{2}-2 \mu\right)}>0$, which is negative definite. Let $\frac{\partial \pi_{s}^{1}}{\partial p_{o}}=0, \frac{\partial \pi_{s}^{1}}{\partial w}=0$, we have the optimal decisions of the supplier as $p_{0}^{1 *}=\frac{1}{2}(c+\mu), w^{1 *}=\frac{1-h}{2}$. Then the retailer's optimal decisions are obtained $p_{r}^{1 *}=\frac{(1-h)\left(3-\alpha^{2}\right)+c(1-\mu)-4 \mu+\mu(3 h+\mu)}{2\left(2-\alpha^{2}-2 \mu\right)}, m^{1 *}=\frac{\alpha(1+c-h-\mu)}{2\left(2-\alpha^{2}-2 \mu\right)}$. By substituting these optimal decisions into Equations (7) and (8), we have the profits of the retailer and the supplier in the dual channel model.

Proof of Proposition 4. From Equation (9), we can find that $\frac{\partial \pi_{r}^{2}}{\partial p_{r}}=\frac{-1+h+2 p_{r}-p_{o}(1+r)-w+\mu}{-1+\mu}$, $\frac{\partial^{2} \pi_{r}^{2}}{\partial p_{r}^{2}}=\frac{2}{-1+\mu}<0, \frac{\partial \pi_{r}^{2}}{\partial m}=-m+\frac{p_{o} r \alpha}{\mu}, \frac{\partial^{2} \pi_{r}^{2}}{\partial m^{2}}=-1<0$, then the Hessian matrix of the retailer is $H\left(p_{r}, m\right)=\left|\begin{array}{cc}\frac{2}{-1+\mu} & 0 \\ 0 & -1\end{array}\right|=\frac{2}{1-\mu}>0$, the Hessian matrix is negative definite. Let $\frac{\partial \pi_{r}^{2}}{\partial p_{r}}=0, \frac{\partial \pi_{r}^{2}}{\partial m}=0$, we have the reaction function of the retailer $p_{r}=$ $\frac{-1+h+2 p_{r}-p_{o}(1+r)-w+\mu}{-1+\mu}, m=\frac{p_{o} r \alpha}{\mu}$. By substituting these reaction functions into Equation (10), we obtain the profit function of the supplier. Then we have $\frac{\partial \pi_{s}^{2}}{\partial w}=\frac{-1+h+2 p_{0}(-1+r)+2 w+\mu}{2(-1+\mu)}$, $\frac{\partial^{2} \pi_{s}^{2 *}}{\partial w^{2}}=\frac{1}{-1+\mu}<0, \frac{\partial \pi_{s}^{2}}{\partial p_{o}}=\frac{(-1+r)\left((1+h+2 w-\mu) \mu^{2}+2 p_{o}\left((-2+\mu) \mu+r\left(-2 \alpha^{2}(-1+\mu)+\mu^{2}\right)\right)\right)}{2(-1+\mu) \mu^{2}}, \frac{\partial^{2} \pi_{s}^{2}}{\partial p_{o}{ }^{2}}=$ $\frac{(-1+r)\left(2 r \alpha^{2}-2 \mu-2 r \alpha^{2} \mu+\mu^{2}+r \mu^{2}\right)}{(-1+\mu) \mu^{2}}<0$. The Hessian matrix of the supplier is $H\left(p_{0}, w\right)=$ $\begin{array}{cc}\frac{(-1+r)\left(2 r \alpha^{2}-2 \mu-2 r \alpha^{2} \mu+\mu^{2}+r \mu^{2}\right)}{(-1+\mu) \mu^{2}} & \frac{1-r}{1-\mu} \\ \frac{1-r}{1-\mu} & \frac{1}{-1+\mu}\end{array} \mid=\frac{2(1-r)\left(\mu-r \alpha^{2}\right)}{(1-\mu) \mu^{2}}$. With the assumption $\bar{\mu}-\alpha^{2}>0$ we know the matrix is negative definite. Let $\frac{\partial \pi_{s}^{2}}{\partial w}=0, \frac{\partial \pi_{s}^{2}}{\partial p_{o}}=0$, we have the optimal decisions of the supplier as $p_{o}^{1 *}=\frac{\mu^{2}}{2\left(-r \alpha^{2}+\mu\right)}, w^{1 *}=\frac{(1-h) \mu-r\left(\mu^{2}+\alpha^{2}(1-h-\mu)\right)}{2 \mu-2 r \alpha^{2}}$. Then the retailer's optimal decisions are obtained $p_{r}^{2 *}=\frac{3 r \alpha^{2}(-1+h+\mu)+\mu(3-3 h-\mu)}{4 \mu-4 r \alpha^{2}}, m^{2 *}=\frac{r \alpha \mu}{2 \mu-2 r \alpha^{2}}$. We substitute them into Equations (9) and (10), then have the profits of the retailer and the supplier in the DFS model. 
Proof of Proposition 5. We compare the equilibrium results in the centralized model. The difference of total market demand in the two models is $D^{c 2}-D^{c 1}=\frac{c \alpha^{2}-2 c \mu-\alpha^{2} \mu}{2\left(\alpha^{2}-2 \mu\right) \mu}>0$. The difference of offline demand is $D_{r}^{c 2 *}-D_{r}^{c 1 *}=\frac{2 c(\mu-1)-\alpha^{2}(1-h-\mu)}{2(1-\mu)\left(2-\alpha^{2}-2 \mu\right)}$, from the assumption of $h<1-\mu$, it is easy to find that $D_{r}^{c 2 *}-D_{r}^{c 1 *}<0$. Similarly, The difference of online demand is $D_{o}^{c 2 *}-D_{o}^{c 1 *}=\frac{c\left(2-\alpha^{2}\right)\left(\alpha^{2}-2 \mu\right)(1-\mu)+\alpha^{4} \mu(2-h-2 \mu)-2 \alpha^{2} \mu(1-\mu-h \mu)}{\left(2\left(\alpha^{2}-2 \mu\right)(1-\mu) \mu\left(2-\alpha^{2}-2 \mu\right)\right)}>0$. For the retailer's freshness-keeping effort $m^{c 2 *}-m^{c 1 *}=\frac{\alpha\left(h \alpha^{2}+2 c \mu-2 h \mu+2 \alpha^{2} \mu-\alpha^{2}-c \alpha^{2}\right)}{\left(\alpha^{2}-2 \mu\right)\left(2-\alpha^{2}-2 \mu\right)}$, let $f=$ $\alpha\left(h \alpha^{2}+2 c \mu-2 h \mu+2 \alpha^{2} \mu-\alpha^{2}-c \alpha^{2}\right), \quad \frac{\partial f}{\partial h}=\alpha\left(\alpha^{2}-2 \mu\right)<0, f_{h=h_{1}}=$ $\frac{\alpha\left(2-\alpha^{2}-2 \mu\right)\left(c \alpha^{2}-2 c \mu-\alpha^{2} \mu\right)}{2 \mu}$. Let $g=f_{h=h_{1}}, \frac{\partial g}{\partial c}=\frac{\alpha\left(\alpha^{2}-2 \mu\right)\left(2-\alpha^{2}-2 \mu\right)}{2 \mu}<0, g_{c=0}=$ $\frac{\alpha\left(\alpha^{2}-2 \mu\right)\left(2-\alpha^{2}-2 \mu\right)}{2 \mu}<0$, therefore, we have $f<0$ from $g<0$. Hence, $m^{c 2 *}-m^{c 1 *}>0$.

Finally, we compare the profit of the supply chain, $\pi^{c 2 *}-\pi^{c 1 *}=$ $c^{2}\left(2-\alpha^{2}\right)\left(2 \mu-\alpha^{2}\right)(1-\mu)-2 c\left(2 h-\alpha^{2}\right)\left(2 \mu-\alpha^{2}\right)(1-\mu) \mu$

$\frac{+\alpha^{2} \mu\left(2 h \mu(h+2 \mu-2)-\alpha^{2}\left((1-h)^{2}+(2 h-3) \mu+2 \mu^{2}\right)\right)}{\left(4\left(\alpha^{2}-2 \mu\right)(1-\mu) \mu\left(2-\alpha^{2}-2 \mu\right)\right)}$, Let $f=c^{2}\left(2-\alpha^{2}\right)$ $\left(\alpha^{2}-2 \mu\right)(1-\mu)-2 c\left(2 h-\alpha^{2}\right)\left(2 \mu \alpha^{2}\right)(1-\mu) \mu+\alpha^{2} \mu\left(2 h \mu(h+2 \mu-2)-\alpha^{2}\left((1-h)^{2}+\right.\right.$ $\left.\left.(2 h-3) \mu+2 \mu^{2}\right)\right)$, we have $\frac{\partial^{2} f}{\partial h^{2}}=\alpha^{2} \mu\left(-2 \alpha^{2}+4 \mu\right)>0$, then we let $f_{h=h_{1}}=$ $\frac{\left(\alpha^{2}-2\right)\left(2-\alpha^{2}-2 \mu\right)\left(c \alpha^{2}-2 c \mu-\alpha^{2} \mu\right)^{2}}{4 \mu}<0$ and $f_{h=h_{0}}=g, \frac{\partial^{2} g}{\partial c^{2}}=2\left(\alpha^{2}-2\right)\left(\alpha^{2}-2 \mu\right)(1-\mu)>0$, $g_{c=c_{0}}=\frac{4(1-\mu)^{2} \mu^{3}\left(2-\alpha^{2}-2 \mu\right)}{\alpha^{2}-2}<0$ and $g_{c=0}=\alpha^{2}(1-\mu) \mu^{2}\left(\alpha^{2}+2 \mu-2\right)<0$. Hence, $f_{h=h_{0}}<0, f_{h=h_{0}}<0$, then $f<0, \pi^{c 2 *}-\pi^{c 1 *}>0$ is proven.

Proof of Proposition 6. We compare the equilibrium results in the decentralized model. It is easy to prove that the difference of demand $D_{t}^{2 *}-D_{t}^{1 *}=\frac{1}{2}-\frac{\mu-c}{2 \mu}=\frac{c}{2 \mu}>0$ and $D_{r}^{2 *}-D_{r}^{1 *}=-\frac{2 c(1-\mu)+\alpha^{2}(1-h-\mu)}{4(1-\mu)\left(2-\alpha^{2}-2 \mu\right)}<0, D_{o}^{2 *}-D_{o}^{1 *}=\frac{\mu \alpha^{2}(1-h-\mu)+2 c(1-\mu)\left(2-\alpha^{2}-\mu\right)}{4 \mu(1-\mu)\left(2-\alpha^{2}-2 \mu\right)}>0$ with $h<1-\mu$ and $\bar{\mu}>\alpha^{2}$.

Next, we prove the retailer' freshness-keeping effort. $m^{2 *}-m^{1 *}=$ $\frac{\alpha\left((1+c-h-\mu) \mu-2 r(1-\mu) \mu-r \alpha^{2}(1+c-h-2 \mu)\right)}{2\left(r \alpha^{2}-\mu\right)\left(2-\alpha^{2}-2 \mu\right)}$, we define $f=\alpha((1+c-h-\mu) \mu-2 r(1-\mu)$ $\left.\mu-r \alpha^{2}(1+c-h-2 \mu)\right)$, then we have $f_{r=0}=\alpha(1+c-h-\mu) \mu>0, f_{r=1}=$ $\alpha \mu(c-h+\mu-1)+\alpha^{3}(h+2 \mu-1-c)$. Note that $\frac{\partial f_{r=1}}{\partial c}=\alpha \mu-\alpha^{3}>0$, and we let $g=$ $\left.\frac{\partial f_{r=1}}{\partial c}\right|_{c=c_{1}}=\frac{\alpha\left(2-\alpha^{2}-2 \mu\right)\left(\mu(\mu-1-h)+\alpha^{2}(1-h-\mu)\right)}{2-\alpha^{2}-\mu}$. It is easy to obtain $\frac{\partial g}{\partial h}=\frac{\alpha\left(\alpha^{2}-\mu\right)\left(2-\alpha^{2}-2 \mu\right)}{2-\alpha^{2}-\mu}$ $<0$ so we have $g_{h=0}=\frac{\alpha(\mu-1)\left(\alpha^{2}+\mu\right)\left(2-\alpha^{2}-2 \mu\right)}{2-\alpha^{2}-\mu}<0$. Hence, $f_{r=1}<0$. We derive $r_{0}=\frac{\mu(1+c-h-\mu)}{2(1-\mu) \mu+\alpha^{2}(1+c-h-2 \mu)}$ from $f=0$. Therefore when $r<r_{0}, m^{2 *}-m^{1 *}<0$ when $r>r_{0}, m^{2 *}-m^{1 *}>0$.

Proof of Proposition 7. For the profit of retailer, we compare $\pi_{r}^{2 *}$ with $\pi_{r}^{1 *}$. Then we have $\pi_{r}^{2 *}-\pi_{r}^{1 *}=\frac{f}{16(-1+\mu)\left(-r \alpha^{2}+\mu\right)^{2}\left(-2+\alpha^{2}+2 \mu\right)}$, where $f=$ $-\alpha^{2} \mu^{2}(-1+h+\mu)^{2}+2 c^{2}(-1+\mu)\left(-r \alpha^{2}+\mu\right)^{2}-4 c(-1+\mu)(-1+h+\mu)\left(-r \alpha^{2}+\mu\right)^{2}+2 r \mu\left(2 \alpha^{2}(-1+\mu) \mu^{2}\right.$ $\left.+4(-1+\mu)^{2} \mu^{2}+\alpha^{4}(-1+h+\mu)^{2}\right)-r^{2} \alpha^{2}\left(6 \alpha^{2}(-1+\mu) \mu^{2}+12(-1+\mu)^{2} \mu^{2}+\alpha^{4}(-1+h+\mu)^{2}\right)$ let $g_{1}=\frac{\partial^{2} f}{\partial r^{2}}$, then $\frac{\partial g_{1}}{\partial h}=8 c \alpha^{4}(1-\mu)+4 \alpha^{6}(1-h-\mu)>0$, we have $\left.\frac{\partial g_{1}}{\partial h}\right|_{h=h_{0}}=4 \alpha^{2}(-1+\mu)$ $\left(c^{2} \alpha^{2}+3 \mu^{2}\left(2-\alpha^{2}-2 \mu\right)\right)<0$. Therefore, $\frac{\partial^{2} f}{\partial r^{2}}<0$. We have $f_{r=0}=\mu^{2}\left(2 c^{2}(-1+\mu)-\right.$ $\left.4 c(-1+\mu)(-1+h+\mu)-\alpha^{2}(-1+h+\mu)^{2}\right)<0$. Then we prove $f$ is increasing at the point $r=0$. We let $g_{2}=\left.\frac{\partial f}{\partial r}\right|_{r=0}=2 \mu\left(-2 c^{2} \alpha^{2}(-1+\mu)+2 \alpha^{2}(-1+\mu) \mu^{2}+4(-1+\mu)^{2} \mu^{2}\right.$ 


$$
\begin{aligned}
& \left.+4 c \alpha^{2}(-1+\mu)(-1+h+\mu)+\alpha^{4}(-1+h+\mu)^{2}\right) \text {, then } \frac{\partial g_{2}}{\partial h}=8 c \alpha^{2}(-1+\mu) \mu+4 \alpha^{4} \mu \\
& (-1+h+\mu)<0 \text {, we have }\left.\frac{\partial g_{2}}{\partial h}\right|_{h=h_{0}}=4(1-\mu) \mu\left(c^{2} \alpha^{2}+\mu^{2}\left(2-\alpha^{2}-2 \mu\right)\right)>0 \text {. Therefore, } \\
& \text { we know that as } r \text { increases from } 0, \pi_{r}^{2 *}-\pi_{r}^{1 *} \text { firstly increases and then decreases. Let } \pi_{r}^{2 *}- \\
& \pi_{r}^{1 *}=0 \text {, and denote the two roots as } r_{1}=\frac{\mu(B-A)-\sqrt{2(A+B)}}{3 B-\alpha^{2} A}, r_{2}=\frac{\mu(B-A)+\sqrt{2(A+B)}}{3 B-\alpha^{2} A} \text {, where } \\
& A=\left(2 c^{2} \alpha^{2}(-1+\mu)-4 c \alpha^{2}(-1+\mu)(-1+h+\mu)-\alpha^{4}(-1+h+\mu)^{2}\right), B=2 \alpha^{2}(-1+\mu) \\
& \mu^{2}+4(-1+\mu)^{2} \mu^{2} \text {. Therefore, if } r_{1}<r<r_{2}, \pi_{r}^{2 *}-\pi_{r}^{1 *}>0 \text {. } \\
& \text { For the profit of the supplier, we have, } \Delta \pi_{s}=\pi_{s}^{2 *}-\pi_{s}^{1 *} \\
& 2 c^{2}\left(r \alpha^{2}-\mu\right)(-1+\mu)\left(-2+\alpha^{2}+\mu\right)-4 c\left(r \alpha^{2}-\mu\right)(-1+\mu) \mu\left(-1-h+\alpha^{2}+\mu\right)+\mu\left(-\alpha^{2} \mu(-1+h+\mu)^{2}\right. \\
& \left.+r\left(2 \alpha^{2}(-2+\mu)(-1+\mu) \mu-4(-1+\mu)^{2} \mu^{2}+\alpha^{4}\left((-1+h)^{2}+2(-2+h) \mu+3 \mu^{2}\right)\right)\right) \\
& \frac{\partial \Delta \pi_{S}}{\partial r}=\frac{\left(\alpha^{2}-\mu\right) \mu^{2}}{4\left(-r \alpha^{2}+\mu\right)^{2}}<0, \Delta \pi_{S} \text { decreases with } r \text {. Let } \Delta \pi_{S}=0 \text {, and denote the root as } \\
& r_{3}=\frac{\mu\left(-4 c\left(1+h-\alpha^{2}-\mu\right)(-1+\mu) \mu-\alpha^{2} \mu(-1+h+\mu)^{2}-2 c^{2}(-1+\mu)\left(-2+\alpha^{2}+\mu\right)\right)}{-2 c^{2} \alpha^{2}(-1+\mu)\left(-2+\alpha^{2}+\mu\right)+4 c \alpha^{2}(-1+\mu) \mu\left(-1-h+\alpha^{2}+\mu\right)+\mu\left(-2 \alpha^{2}(-2+\mu)(-1+\mu) \mu\right.} . \\
& \text { Therefore, if } r<r_{3}, \Delta \pi_{s}>0 \text {. }
\end{aligned}
$$

\section{References}

1. Ministry of Commerce of the People's Republic of China (Mofcom). Available online: http://www.mofcom.gov.cn/article/i/jyjl/ j/202101/20210103033716.shtml (accessed on 25 January 2021).

2. IResearch. Available online: https:/ / www.iresearch.com.cn/report.shtml (accessed on 13 July 2020).

3. He, B.; Gan, X.; Yuan, K. Entry of online presale of fresh produce: A competitive analysis. Eur. J. Oper. Res. 2019, $272,339-351$. [CrossRef]

4. Liu, L.; Feng, L.; Xu, B.; Deng, W. Operation strategies for an omnichannel supply chain: Who is better off taking on the online channel and offline service? Electron. Commer. Res. Appl. 2020, 39, 100918. [CrossRef]

5. Blackburn, J.; Scudder, G. Supply chain strategies for perishable products: The case of fresh produce. Prod. Oper. Manag. 2009, 18, 129-137. [CrossRef]

6. Emarketer. Available online: https://www.emarketer.com/chart/230850/us-internet-users-whose-concern-about-temperaturefreshness-of-fresh-frozen-food-items-reason-they-have-not-ordered-them-online-home-delivery-aug-2019-of-respondentsby-age (accessed on 3 September 2019).

7. Liu, C.; Chen, W.; Zhou, Q.; Mu, J. Modelling dynamic freshness-keeping effort over a finite time horizon in a two-echelon online fresh product supply chain. Eur. J. Oper. Res. 2021, 293, 511-528. [CrossRef]

8. $\mathrm{Wu}, \mathrm{Q} . ; \mathrm{Mu}, \mathrm{Y}$;; Feng, Y. Coordinating contracts for fresh product outsourcing logistics channels with power structures. Int. J. Prod. Econ. 2015, 160, 94-105. [CrossRef]

9. Yu, Y.; Xiao, T. Analysis of cold-chain service outsourcing modes in a fresh agri-product supply chain. Transp. Res. Part E Logist. Transp. Rev. 2021, 148, 102264. [CrossRef]

10. Choudhary, A.; De, A.; Ahmed, K.; Shankar, R. An integrated fuzzy intuitionistic sustainability assessment framework for manufacturing supply chain: A study of UK based firms. Ann. Oper. Res. 2021. [CrossRef]

11. Bai, H.; Guo, Q. Analysis on the influencing factors of the development of Chinese fresh cold chain logistics under e-commerce background. J. Manag. Strategy 2017, 8, 55-60. [CrossRef]

12. Yan, B.; Chen, X.; Cai, C.; Guan, S. Supply chain coordination of fresh agricultural products based on consumer behavior. Comput. Oper. Res. 2020, 123, 105038. [CrossRef]

13. Musso, F. Innovation in marketing channels: Relationships, technology, channel structure. Symph. Emerg. Issues Manag. 2010, 1, 23-42.

14. He, B.; Gupta, V.; Mirchandani, P. Online selling through O2O platform or on your own? Strategic implications for local Brick-and-Mortar stores. Omega 2021, 103, 102424. [CrossRef]

15. Lin, X.; Zhou, Y.W.; Hou, R. Impact of a "buy-online-and-pickup-in-store" channel on price and quality decisions in a supply chain. Eur. J. Oper. Res. 2020. [CrossRef]

16. Melero, I.; Sese, F.J.; Verhoef, P.C. Recasting the customer experience in today's omnichannel environment. Universia Bus. Rev. 2016, 50, 18-37.

17. He, Y.; Xu, Q.; Shao, Z. “Ship-from-store” strategy in platform retailing. Transp. Res. Part E Logist. Transp. Rev. 2021, 145, 102153. [CrossRef]

18. Gallino, S.; Moreno, A.; Stamatopoulos, I. Channel integration, sales dispersion, and inventory management. Manag. Sci. 2017, 63, 2813-2831. [CrossRef]

19. Hossain, T.M.T.; Akter, S.; Kattiyapornpong, U.; Dwivedi, Y. Reconceptualizing Integration Quality Dynamics for Omnichannel Marketing. Ind. Mark. Manag. 2020, 87, 225-241. [CrossRef] 
20. Mishra, R.; Singh, R.K.; Koles, B. Consumer decision-making in Omnichannel retailing: Literature review and future research agenda. Int. J. Consum. Stud. 2021, 45, 147-174. [CrossRef]

21. Gerea, C.; Gonzalez-Lopez, F.; Herskovic, V. Omnichannel customer experience and management: An integrative review and research agenda. Sustainability 2021, 13, 2824. [CrossRef]

22. Kang, J.; Majer, M.; Kim, H.J. Empirical study of omnichannel purchasing pattern with real customer data from health and lifestyle company. Sustainability 2019, 11, 7185. [CrossRef]

23. Rodríguez-Torrico, P.; Cabezudo, R.S.J.; San-Martín, S. Tell me what they are like and I will tell you where they buy. An analysis of omnichannel consumer behavior. Comput. Hum. Behav. 2017, 68, 465-471. [CrossRef]

24. Thaichon, P.; Phau, I.; Weaven, S. Moving from multi-channel to omnichannel retailing: Special issue introduction. J. Retail. Consum. Serv. 2020. [CrossRef]

25. Cui, T.H.; Ghose, A.; Halaburda, H.; Iyengar, R.; Pauwels, K.; Sriram, S.; Tucker, C.; Venkataraman, S. Informational Challenges in Omnichannel Marketing: Remedies and Future Research. J. Mark. 2021, 85, 103-120. [CrossRef]

26. Verhoef, P.C.; Kannan, P.K.; Inman, J.J. From multi-channel retailing to omni-channel retailing: Introduction to the special issue on multi-channel retailing. J. Retail. 2015, 91, 174-181. [CrossRef]

27. Palmatier, R.W.; Stern, L.W.; El-Ansary, A.I. Marketing Channel Strategy: An Omni-Channel Approach; Routledge: London, UK, 2016; pp. 3-13.

28. Musso, F. Destructuring of Marketing Channels and Growth of Multichannelling. In Search of a New Model for Distribution Systems. In Competitive Business Management. A Global Perspective; Brondini, S.M., Ed.; Routledge: London, UK, 2018 ; pp. 125-136.

29. Aubrey, C.; Judge, D. Re-imagine retail: Why store innovation is key to a brand's growth in the "new normal", digitally-connected and transparent world. J. Brand Strategy 2012, 1, 31-39.

30. Gao, F.; Su, X. Omnichannel retail operations with buy-online-and-pick-up-in-store. Manag. Sci. 2017, 63, 2478-2492. [CrossRef]

31. Jiang, Y.; Liu, L.; Lim, A. Optimal pricing decisions for an omni-channel supply chain with retail service. Int. Trans. Oper. Res. 2020, 27, 2927-2948. [CrossRef]

32. Kong, R.; Luo, L.; Chen, L.; Keblis, M.F. The effects of BOPS implementation under different pricing strategies in omnichannel retailing. Transp. Res. Part E Logist. Transp. Rev. 2020, 141, 102014. [CrossRef]

33. Song, Y.; Fan, T.; Tang, Y.; Xu, C. Omnichannel strategies for fresh produce with extra losses in-store. Transp. Res. Part E Logist. Transp. Rev. 2021, 148, 102243. [CrossRef]

34. Jin, M.; Li, G.; Cheng, T.C.E. Buy online and pick up in-store: Design of the service area. Eur. J. Oper. Res. 2018, $268,613-623$. [CrossRef]

35. Zhang, P.; He, Y.; Zhao, X. "Preorder-online, pickup-in-store" strategy for a dual-channel retailer. Transp. Res. Part E Logist. Transp. Rev. 2019, 122, 27-47. [CrossRef]

36. Zhang, J.; Xu, Q.; He, Y. Omnichannel retail operations with consumer returns and order cancellation. Transp. Res. Part E Logist. Transp. Rev. 2018, 118, 308-324. [CrossRef]

37. Nageswaran, L.; Cho, S.H.; Scheller-Wolf, A. Consumer return policies in omnichannel operations. Manag. Sci. 2020, 66, 5558-5575. [CrossRef]

38. Jin, D.; Caliskan-Demirag, O.; Chen, F.Y.; Huang, M. Omnichannel retailers' return policy strategies in the presence of competition. Int. J. Prod. Econ. 2020, 225, 107595. [CrossRef]

39. Bayram, A.; Cesaret, B. Order fulfillment policies for ship-from-store implementation in omnichannel retailing. Eur. J. Oper. Res. 2020. [CrossRef]

40. Yang, D.; Zhang, X. Omnichannel operations with ship-from-store. Oper. Res. Lett. 2020, 48, 257-261. [CrossRef]

41. He, P.; He, Y.; Xu, H. Buy-online-and-deliver-from-store strategy for a dual-channel supply chain considering retailer's location advantage. Transp. Res. Part E Logist. Transp. Rev. 2020, 144, 102127. [CrossRef]

42. Li, G.; Li, L.; Sun, J. Pricing and service effort strategy in a dual-channel supply chain with showrooming effect. Transp. Res. Part E Logist. Transp. Rev. 2019, 126, 32-48. [CrossRef]

43. Du, S.; Wang, L.; Hu, L. Omnichannel management with consumer disappointment aversion. Int. J. Prod. Econ. 2019, 215, 84-101. [CrossRef]

44. Shen, X.L.; Li, Y.J.; Sun, Y.; Wang, N. Channel integration quality, perceived fluency and omnichannel service usage: The moderating roles of internal and external usage experience. Decis. Support Syst. 2018, 109, 61-73. [CrossRef]

45. Kim, K.; Han, S.L.; Jang, Y.Y.; Shin, Y.C. The effects of the antecedents of "Buy-Online-Pick-Up-In-Store" service on consumer's BOPIS choice behaviour. Sustainability 2020, 12, 9989. [CrossRef]

46. Song, Z.; He, S. Contract coordination of new fresh produce three-layer supply chain. Ind. Manag. Data Syst. 2019, 119, 148-169. [CrossRef]

47. Zheng, Q.; Zhou, L.; Fan, T.; Ieromonachou, P. Joint procurement and pricing of fresh produce for multiple retailers with a quantity discount contract. Transp. Res. Part E Logist. Transp. Rev. 2019, 130, 16-36. [CrossRef]

48. Ge, H.; Goetz, S.; Canning, P.; Perez, A. Optimal locations of fresh produce aggregation facilities in the United States with scale economies. Int. J. Prod. Econ. 2018, 197, 143-157. [CrossRef]

49. Cai, X.; Chen, J.; Xiao, Y.; Xu, X. Optimization and coordination of fresh product supply chains with freshness-keeping effort. Prod. Oper. Manag. 2010, 19, 261-278. [CrossRef] 
50. Liu, M.; Dan, B.; Zhang, S.; Ma, S. Information sharing in an E-tailing supply chain for fresh produce with freshness-keeping effort and value-added service. Eur. J. Oper. Res. 2021, 290, 572-584. [CrossRef]

51. Zheng, Q.; Ieromonachou, P.; Fan, T.; Zhou, L. Supply chain contracting coordination for fresh products with fresh-keeping effort. Ind. Manag. Data Syst. 2017, 117, 538-559. [CrossRef]

52. Chernonog, T. Inventory and marketing policy in a supply chain of a perishable product. International. J. Prod. Econ. 2020, 219, 259-274. [CrossRef]

53. Yang, L.; Tang, R. Comparisons of sales modes for a fresh product supply chain with freshness-keeping effort. Transp. Res. Part E Logist. Transp. Rev. 2019, 125, 425-448. [CrossRef]

54. Hu, Q.; Xu, B. Differential game analysis of optimal strategies and cooperation in omni-channel organic agricultural supply chain. Sustainability 2019, 11, 848. [CrossRef]

55. Chiang, W.Y.K.; Chhajed, D.; Hess, J.D. Direct marketing, indirect profits: A strategic analysis of dual-channel supply-chain design. Manag. Sci. 2003, 49,1-20. [CrossRef]

56. Yang, F.; Wang, M.; Ang, S. Optimal remanufacturing decisions in supply chains considering consumers' anticipated regret and power structures. Transp. Res. Part E Logist. Transp. Rev. 2021, 148, 102267. [CrossRef]

57. Zhang, P.; He, Y.; Shi, C.V. Retailer's channel structure choice: Online channel, offline channel, or dual channels? Int. J. Prod. Econ. 2017, 191, 37-50. [CrossRef]

58. Wang, C.; Leng, M.; Liang, L. Choosing an online retail channel for a manufacturer: Direct sales or consignment? Int. J. Prod. Econ. 2018, 195, 338-358. [CrossRef]

59. Cai, X.; Chen, J.; Xiao, Y.; Xu, X.; Yu, G. Fresh-product supply chain management with logistics outsourcing. Omega 2013, 41, 752-765. [CrossRef]

60. Dan, B.; Zhang, H.; Zhang, X.; Guan, Z.; Zhang, S. Should an online manufacturer partner with a competing or noncompeting retailer for physical showrooms? Int. Trans. Oper. Res. 2020, 28, 2691-2714. [CrossRef]

61. Zhang, J.; Liu, G.; Zhang, Q.; Bai, Z. Coordinating a supply chain for deteriorating items with a revenue sharing and cooperative investment contract. Omega 2015, 56, 37-49. [CrossRef]

62. Wang, C.; Chen, X. Option pricing and coordination in the fresh produce supply chain with portfolio contracts. Ann. Oper. Res. 2017, 248, 471-491. [CrossRef]

63. Goswami, M.; Daultani, Y.; De, A. Decision modeling and analysis in new product development considering supply chain uncertainties: A multi-functional expert based approach. Expert Syst. Appl. 2021, 166, 114016. [CrossRef] 